\title{
Social media use in the research workflow
}

\author{
Professors David Nicholas* and Ian Rowlands \\ CIBER Research Ltd, Newbury, Berkshire, UK
}

\begin{abstract}
The paper reports on a major international questionnaire survey that investigated the use of social media in the research workflow. The topic is the second to emerge from the Charleston Observatory. The study of more than 2000 researchers shows that social media impact on all points of the research lifecycle, from identifying research opportunities to disseminating findings at the end. The three most popular social media tools in a research setting were those for collaborative authoring, conferencing, and scheduling meetings. The most popular brands used tend to be mainstream anchor technologies or 'household brands', like Twitter and Skype. Age is a poor predictor of social media use in a research context and scientists avail themselves most of social media. Journals, conference proceedings and edited books remain the core traditional means of disseminating research, with institutional repositories highly valued as well, but social media has become an important complementary channel for disseminating and discovering research.
\end{abstract}

Keywords: Social media, Web 2.0, user surveys, research process, implications for publishers

\section{Introduction}

The CIBER research group has been investigating the behavior of the virtual scholar for some ten years. During this time we have investigated the use and impact of e-journals, e-books, Big Deals, Google, the Google Generation, open access publishing and gateways. Our most recent research examines the use and impact of what looks like becoming the next 'big thing', social media. To get a publishing purchase on the topic we chose to investigate the impact of social media tools on research work flow. At the heart of the research was a major international survey, covering 2000 researchers, and the early findings are presented in this paper [1].

\section{Background}

Social media, like Twitter and Facebook, have made an enormous impact on many people's personal lives, but we have only a sketchy understanding of how researchers are using them and, if so, for what purposes and how they fit into the research life cycle; and how this all impacts on publishers, who might well feel threatened by the social tsunami [2].

The study was a large international one and conducted at the backend of 2010. The study was the second one to emerge from the Charleston Observatory [4], the research adjunct of the popular Charleston Conference, and funded by Emerald, and set out to answer these questions:

(a) Are social media impacting upon researcher workflows?

(b) How influential are age and other factors in shaping the demand for social media?

(c) If so, how should publishers respond?

\footnotetext{
${ }^{*}$ Corresponding author: David Nicholas, CIBER Research Ltd, 1 Westwood Farm, New Road, Greenham, Newbury, Berkshire, RG14 7RU, UK. E-mail: Dave.Nicholas@ ciber-research.eu.
} 


\section{Methodology}

Invitations to take part in an online questionnaire survey were sent out by email by co-operating publishers (Wiley, T\&F, Emerald, Kluwer and CUP). The publisher mailing was supplemented by an emailing to researchers at University College London and delegates attending the Charleston Conference 2010. In all nearly 100,000 people obtained invitations and 4012 people responded to the survey. This paper focuses on the 2414 researchers who responded (publishers, librarians and university administrators also responded to the questionnaire). It is estimated the response rate was $6 \%$.

This was a large sample by any standards and because the survey was distributed through multiple and diverse channels we were able to reach all disciplines across a very wide geographic range (with responses from 215 countries). Any systematic biases in one mailing list were likely to have been at least partially offset by different biases in the others. The final dataset constitutes a "non-probabilistic convenience sample". That means that we cannot generalize from these findings to the whole population of researchers with any confidence.

This paper then is an exploratory data analysis of the preferences, perceptions and self-reported behaviour of nearly two thousand (1923) researchers who are currently using social media tools to support their research activities. In the analysis presented here a contrast group of 491 researchers who have yet to use social media were used to get a little closer to understanding the factors that shape demand and take up using.

Of course questionnaires often raise more questions than they answer and the authors of this paper are currently running focus groups with authors and editors of some of the co-operating publishers and with librarians and academics at major UK universities ${ }^{1}$ in order to obtain explanation and clarification of the questionnaire findings.

\section{Results}

\subsection{What social media tools do academics use in their research?}

The study deliberately sought a sample that was rich with academics that are currently using social media in their research. We could have framed the survey invitation differently, to draw on a truly representative random sample of opinion about social media, but we chose not to. No attempt is made in this report to claim that so many percent of academics use social media. Our email invitation was deliberately couched in such a way that we actively encouraged social media users to complete the questionnaire. To use an analogy, we are really interested in the views of drivers, not non-drivers, when it comes to their preferences for driving gloves.

In this first part of the paper (Sections 4.1 and 4.2), however, we compare survey completions by the 1923 researchers who said they are currently using at least one category of social media tools for research purposes, and contrast them with a control group of 491 researchers who have yet to make use of any social media tools at all. The purpose is to try to find some answers to the questions like 'Who uses social media in their research?' and 'What tools do they use?'.

The survey asked respondents specifically about their use in research of eight categories of social media tools:

\footnotetext{
${ }^{1}$ The university dimension of the study is funded by the Research Information Network.
} 


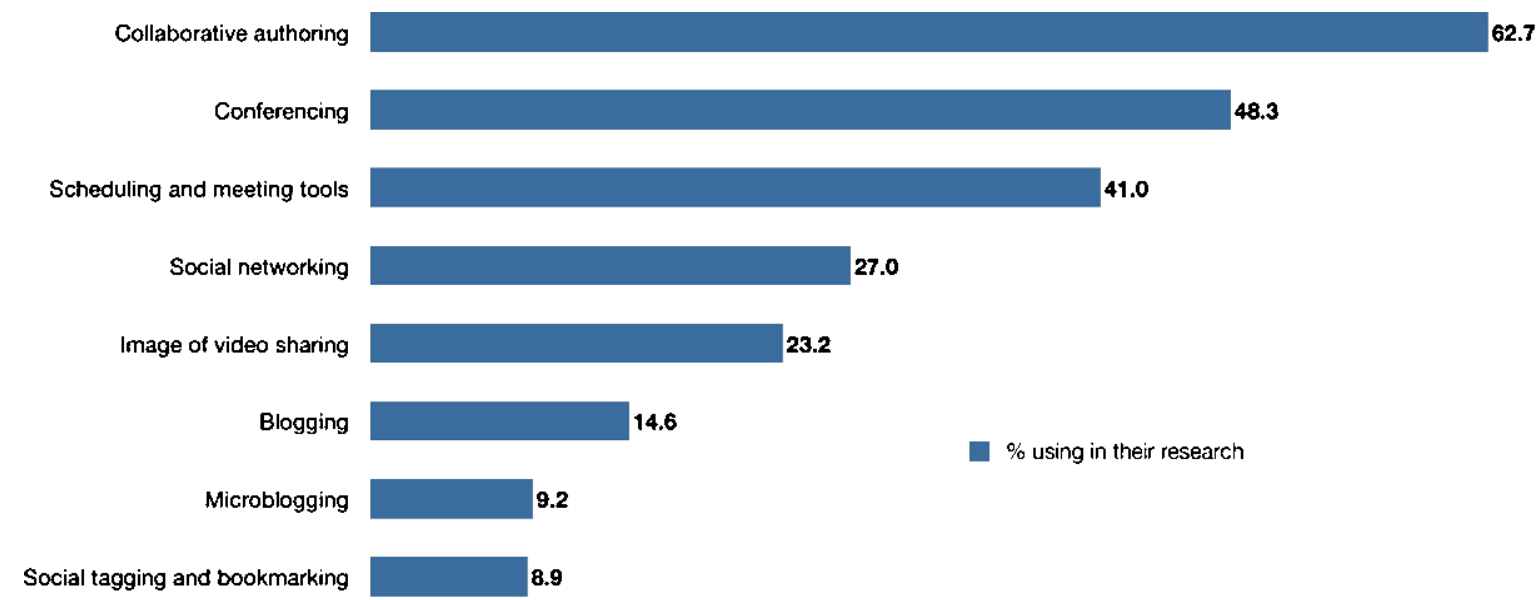

Fig. 1. Popularity of various types of social media in research. Active social media users: percentages using each category of tool. (Colors are visible in the online version of the article; http://dx.doi.org/10.3233/ISU-2011-0623.)

- Social networking.

- Blogging.

- Microblogging.

- Collaborative authoring.

- Social tagging and bookmarking.

- Scheduling and meeting tools.

- Conferencing.

- Image or video sharing.

These categories were defined by example in the questionnaire: so for each we offered a list of generic and research-specific tools (such as Nature Network, LinkedIn and Facebook to exemplify the kinds of tools that fall under the social networking umbrella).

The relative popularity of these tools among active social media users is shown in Fig. 1. The percentages add up to more than 100 since many researchers are using tools in more than one category. Collaborative authoring is by some distance the most popular tool, and social tagging and microblogging the least popular (see Fig. 2).

In fact, a large majority (63.4\%) of researchers uses tools in only one or two categories, and very few researchers are using the full gamut of what is possible.

This raises the question of which tools 'go together' when academics start to incorporate social media into their research workflow? Table 1 is a correlation matrix, where pairs of tools that are often used by the same researcher are indicated by higher values. Small or negative values indicate that a particular pair of tools is rarely used by the same researcher.

In this matrix, the two most common tool pairings are blogging/microblogging (Pearson correlation $0.46)$ and social networking/microblogging (0.42). The relationships may be easier to see if the data in Table 1 are presented in a more visual form as a heat map (Fig. 3), where intense green means that the tools are often used by the same person, and red means this is rarely the case.

Further evidence that the take up of social media tools is structured in some way can be seen in the results of an automatic classification (Fig. 4) using cluster analysis. This strongly suggests that there are two broad kinds of academic social media user. The first group makes considerable joint use of mi- 


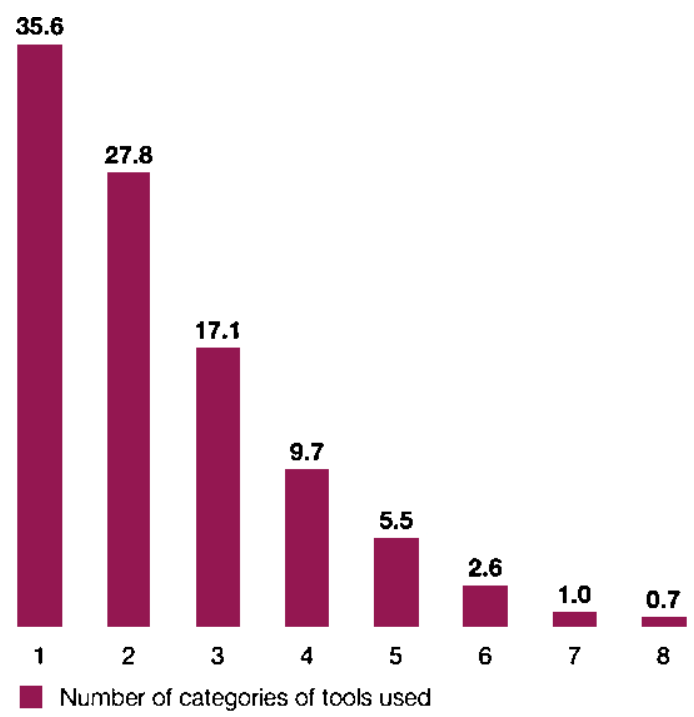

Fig. 2. Popularity of various types of social media in research. Active social media users: percentages using each category of tool. (Colors are visible in the online version of the article; http://dx.doi.org/10.3233/ISU-2011-0623.)

Table 1

Use of social media in research: correlation matrix. Pearson coefficients (two-tailed)

\begin{tabular}{|c|c|c|c|c|c|c|c|c|}
\hline & $\begin{array}{c}\text { Social } \\
\text { networking }\end{array}$ & Blogging & Microblogging & $\begin{array}{c}\text { Collaborative } \\
\text { authoring }\end{array}$ & $\begin{array}{c}\text { Social tagging } \\
\text { and bookmarking }\end{array}$ & Scheduling & Conferencing & $\begin{array}{c}\text { Image and } \\
\text { video sharing }\end{array}$ \\
\hline $\begin{array}{l}\text { Social } \\
\text { networking }\end{array}$ & & $0.28^{* *}$ & $0.42^{* *}$ & -0.02 & $0.27^{* *}$ & $0.16^{* *}$ & $0.16^{* *}$ & $0.26^{* *}$ \\
\hline Blogging & $0.28^{* *}$ & & $0.46^{* *}$ & $0.10^{* *}$ & $0.35^{* *}$ & $0.15^{* *}$ & $0.11^{* *}$ & $0.28^{* *}$ \\
\hline Microblogging & $0.42^{* *}$ & $0.46^{* *}$ & & $0.09^{* *}$ & $0.39^{* *}$ & $0.25^{* *}$ & $0.14^{* *}$ & $0.31^{* *}$ \\
\hline $\begin{array}{l}\text { Collaborative } \\
\text { authoring }\end{array}$ & -0.02 & $0.10^{* *}$ & $0.10^{* *}$ & & 0.03 & $-0.5 *$ & $-0.10^{* *}$ & $0.10^{* *}$ \\
\hline $\begin{array}{l}\text { Social tagging, } \\
\text { bookmarking }\end{array}$ & $0.27^{* *}$ & $0.35^{* *}$ & $0.39^{* *}$ & 0.03 & & $0.23^{* *}$ & $0.07^{* *}$ & $0.20^{* *}$ \\
\hline Scheduling & $0.16^{* *}$ & $0.15^{* *}$ & $0.25^{* *}$ & $-0.5^{*}$ & $0.23^{* *}$ & & $0.17^{* *}$ & $0.10^{* *}$ \\
\hline Conferencing & $0.16^{* *}$ & $0.11^{* *}$ & $0.14^{* *}$ & $-0.10^{* *}$ & $0.07^{* *}$ & $0.17^{* *}$ & & $0.12^{* *}$ \\
\hline $\begin{array}{l}\text { Image and } \\
\text { video sharing }\end{array}$ & $0.26^{* *}$ & $0.28^{* *}$ & $0.31^{* *}$ & $0.10^{* *}$ & $0.17^{* *}$ & $0.10^{* *}$ & $0.10^{* *}$ & \\
\hline
\end{tabular}

croblogging, social tagging/bookmarking and blogging. These researchers are also more likely to engage in social networking and image or video sharing. The other group focuses around longer established social media tools for scheduling meetings, organizing their diaries and sharing documents. Whether this dichotomy represents a real schism, or whether the gap will close as social media tools gain more traction remains to be seen.

This interpretation certainly fits with the data in Fig. 5, which breaks out the users of each social media tool by their innovation characteristics [3]. The tools that characterize our first cluster above are also those which are the least established: those for which the smallest numbers of early and late majority and laggards have yet expressed an interest. 
social networking

\section{Blogging}

Microblogging

Collaborative authoring

social tagging, bookmarking

\section{scheduling}

\section{Conferencing}

\section{Image or video sharing}

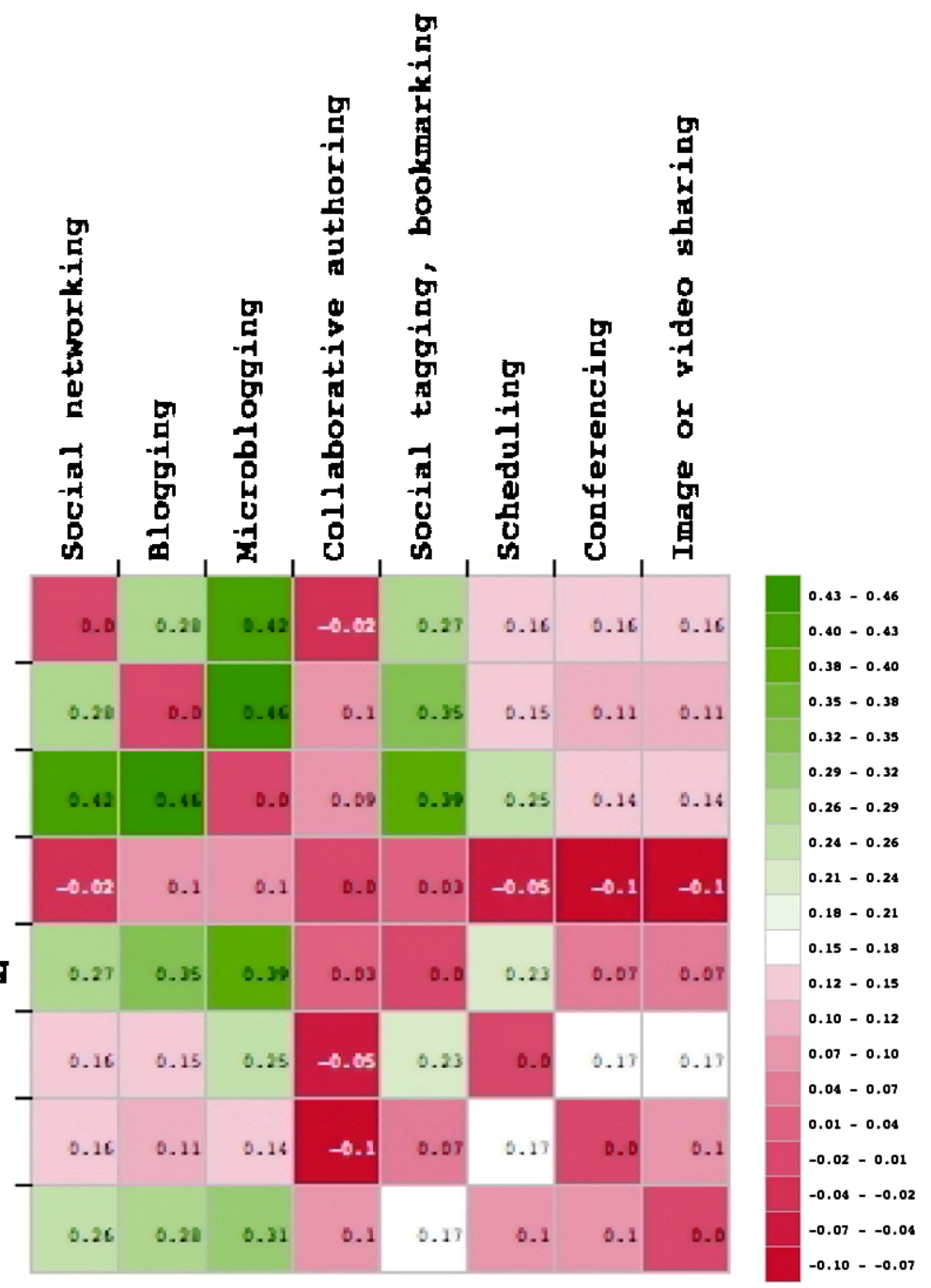

Fig. 3. Use of social media in research. Heat map of the data in Table 1. (Colors are visible in the online version of the article; http://dx.doi.org/10.3233/ISU-2011-0623.)

Figure 6 shows which social media tools have the lowest (and highest) current levels of awareness among researchers. While this analysis does not demonstrate that social networking and (micro) blogging will become much bigger feature of the research landscape with any certainty, the direction of travel is clear and that outcome cannot be discounted.

\subsection{Who uses social media in their research?}

Since we have a contrast group of researchers who do not use social media, we are in a position to compare and contrast them with those who have already taken up the challenge. This should give us a better insight into the demographics of current users, and this may offer pointers to the future. There are quite large differences in the take up of social media by subject discipline (Table 2). 


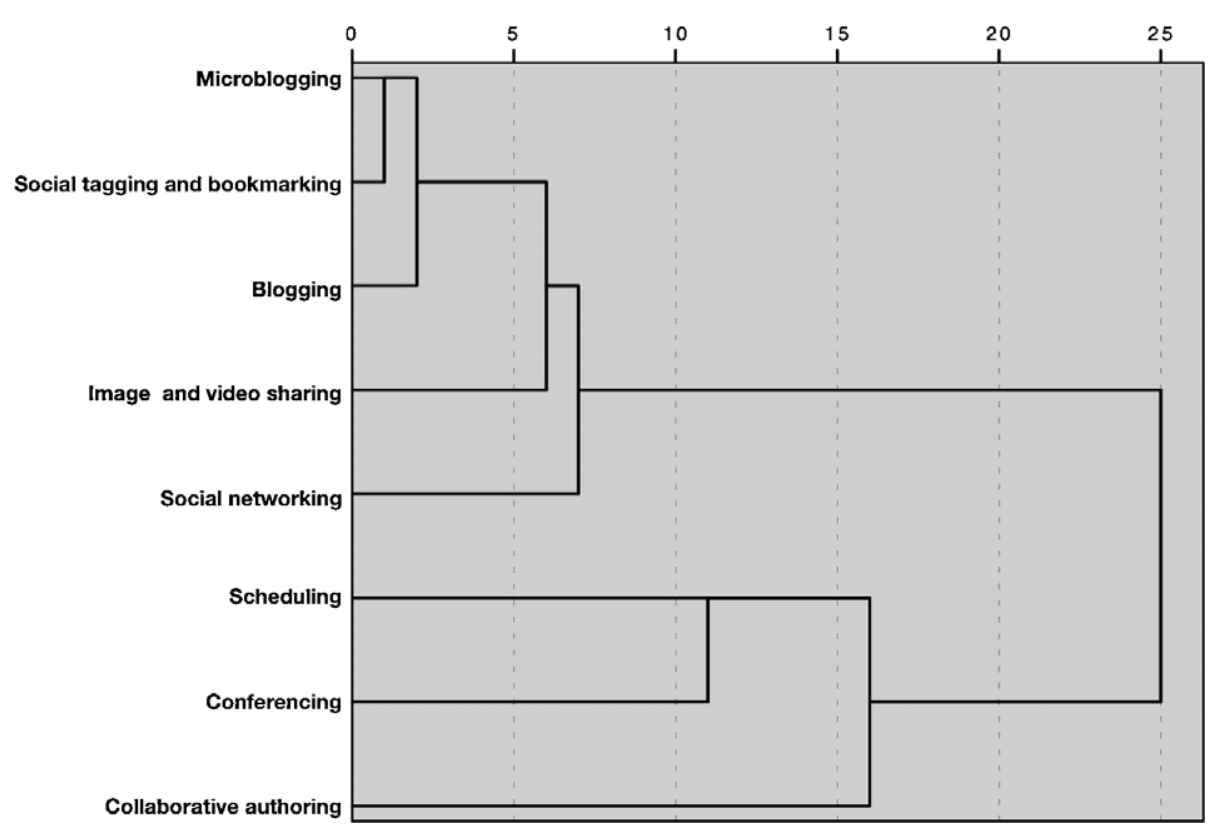

Fig. 4. Use of social media in research: cluster analysis. Dendrogram (Ward's method, squared Euclidean distances.

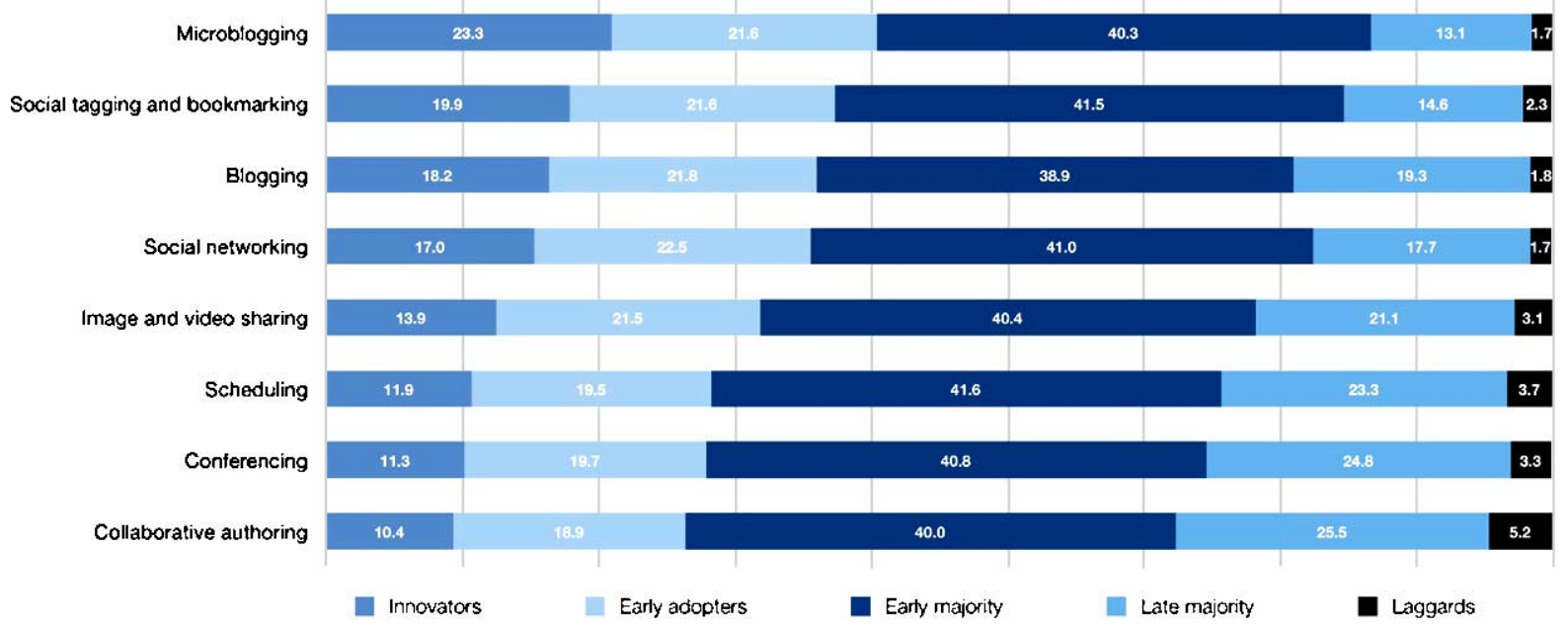

Fig. 5. Use of social media in research: innovation behaviour by category. Percentages of Rogers' innovation types within each tool category. (Colors are visible in the online version of the article; http://dx.doi.org/10.3233/ISU-2011-0623.)

Using a tree classification (an automatic procedure for detecting similar subgroups using chi-squared statistics) we can see, in Fig. 7, that there is a big divide of nearly ten percentage points along subject lines. Academics in business, health, the biosciences, and the arts and humanities are less likely to use social media for research purposes than their peers in other parts of the academy.

As well as subject, personal research style is a powerful predictor of social media take-up. The survey asked respondents, generally speaking, which one of the following options best described their style of research working? 


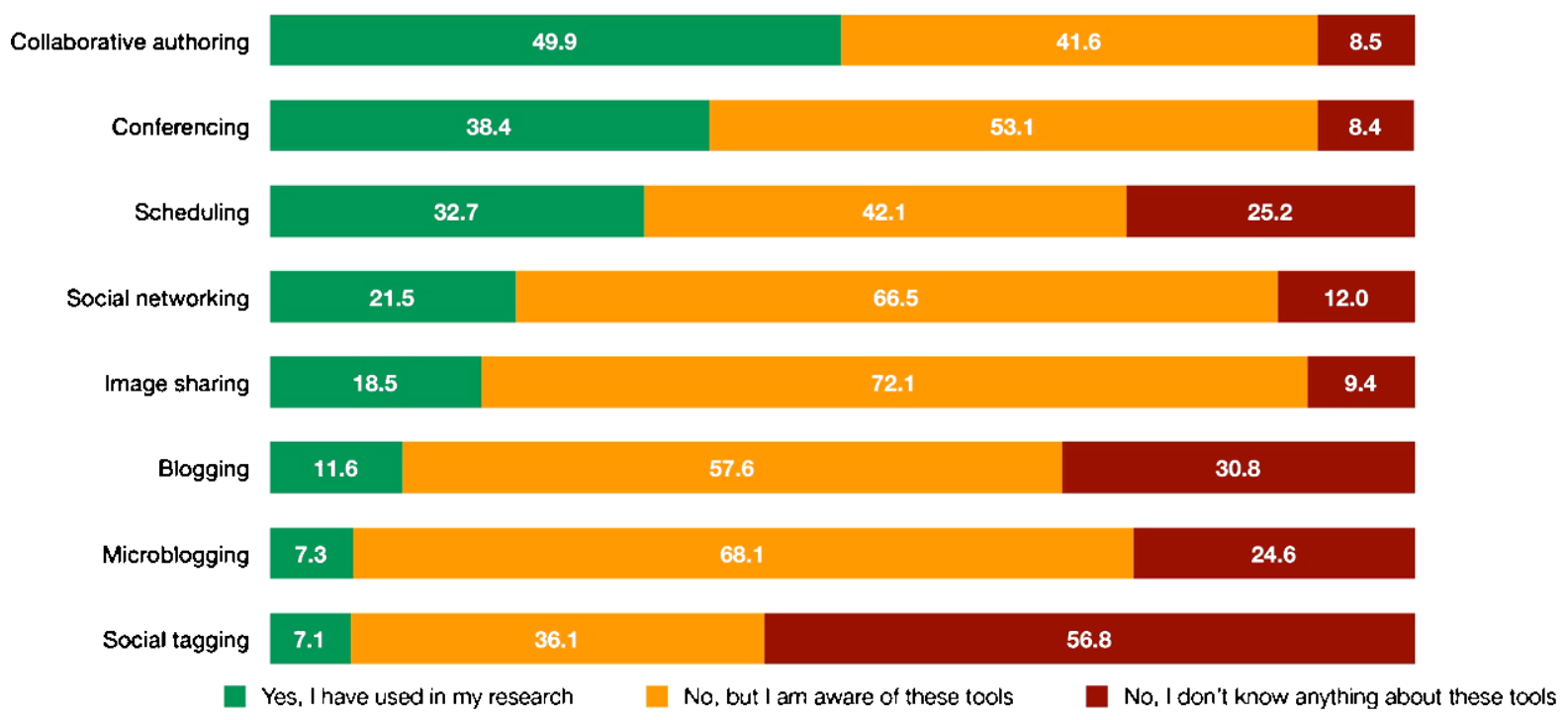

Fig. 6. Use and awareness of social media in research by type of tool. Yes - researchers who use any social media tools. (Colors are visible in the online version of the article; http://dx.doi.org/10.3233/ISU-2011-0623.)

Table 2

Use and non-use of social media in research by narrow subject discipline. Percentages within disciplines

\begin{tabular}{lrr}
\hline & \multicolumn{2}{c}{ Use social media tools in research } \\
\cline { 2 - 3 } & No & Yes \\
\hline Earth sciences & 5.0 & 95.0 \\
Environmental sciences & 10.0 & 90.0 \\
Physics & 11.4 & 88.6 \\
Pharmacology and toxicology & 12.5 & 87.5 \\
Neuroscience & 13.0 & 87.0 \\
Life sciences & 15.8 & 84.2 \\
Social sciences & 16.0 & 84.0 \\
Mathematics and computer science & 16.3 & 83.7 \\
Chemistry and chemical engineering & 17.8 & 82.2 \\
Materials science and engineering & 17.9 & 82.1 \\
Arts and humanities & 20.8 & 79.2 \\
Biological sciences & 21.7 & 78.3 \\
Health sciences & 25.2 & 74.8 \\
Business and management & 26.3 & 73.7 \\
All disciplines & $\mathbf{2 0 . 3}$ & $\mathbf{7 9 . 7}$ \\
\hline
\end{tabular}

- I work with collaborators in different institutions.

- I work with colleagues across my institution.

- I work with colleagues in my own department.

- I work on my own research or scholarship.

The answer to this question opens up a statistically significant gap between those who chose the first option and the rest (Fig. 8). That social media should be valued especially by academics whose pre- 


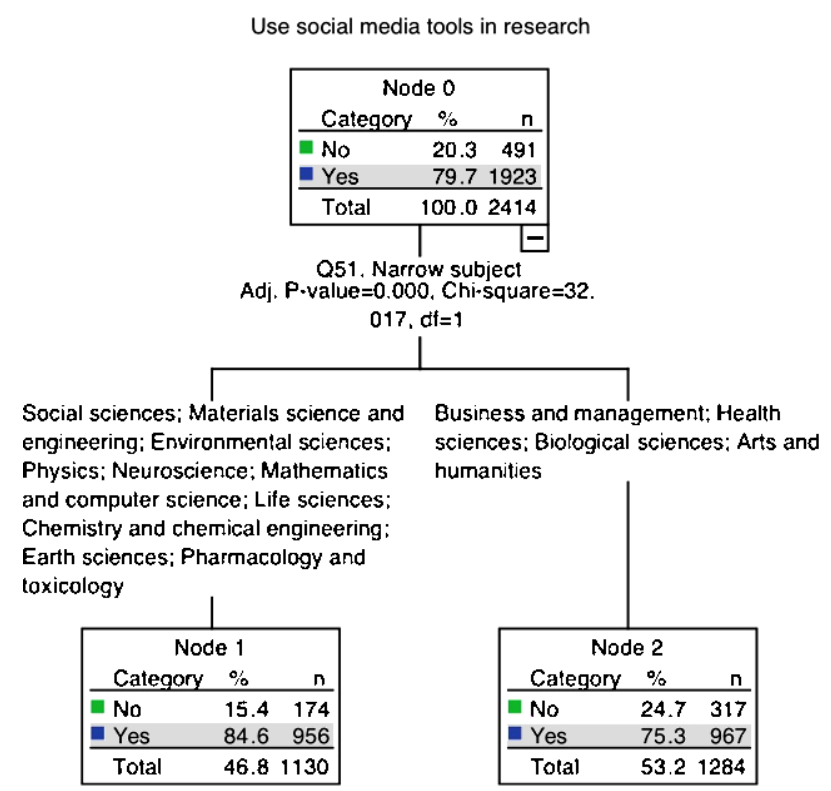

Fig. 7. Use of social media in research by narrow subject discipline. Classification tree and chi-squared statistics. (Colors are visible in the online version of the article; http://dx.doi.org/10.3233/ISU-2011-0623.)

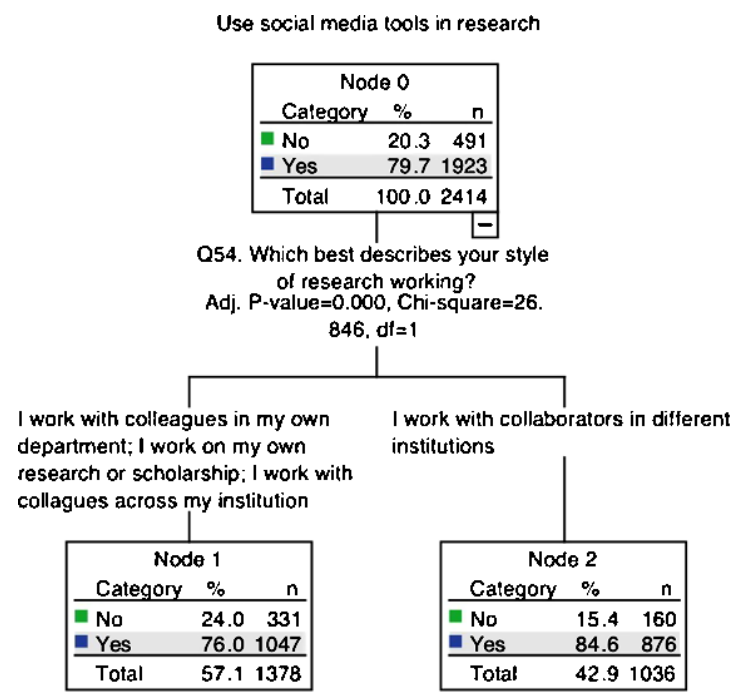

Fig. 8. Use of social media in research by preferred research style. Classification tree and chi-squared statistics. (Colors are visible in the online version of the article; http://dx.doi.org/10.3233/ISU-2011-0623.)

dominant mode of research work is across institutional boundaries is hardly surprising, but this analysis quantifies that difference: these researchers are 1.11 times more likely than the rest to use social media.

Age is an interesting demographic when it comes to the use of social media in research. Broadly speaking, there is a break point around 35 years (Fig. 9). Researchers younger than this are significantly more likely $(82.6 \%)$ to use social media professionally than the older group (75.7\%). This effect is statistically significant, but it is not large. 


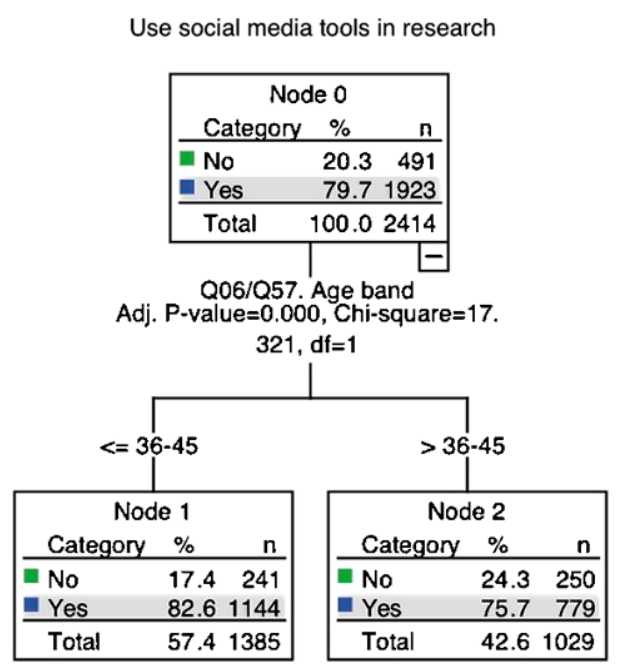

Fig. 9. Use of social media in research by age group. Classification tree and chi-squared statistics. (Colors are visible in the online version of the article; http://dx.doi.org/10.3233/ISU-2011-0623.)

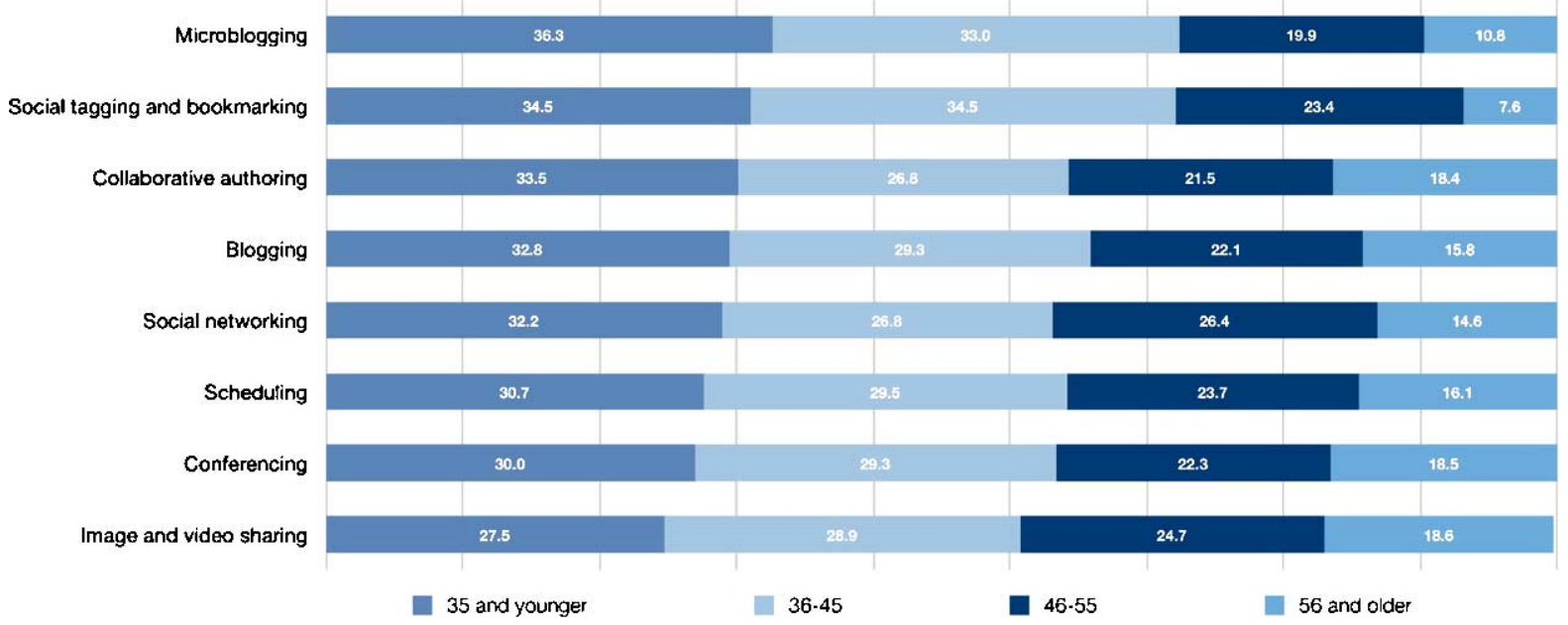

Fig. 10. Use of social media tools by age group. Researchers who use at least one social media tool in their research. (Colors are visible in the online version of the article; http://dx.doi.org/10.3233/ISU-2011-0623.)

This is a very crude simplification, however, since it pulls together researchers who happen to use any of eight categories of social media tools. A more detailed picture is revealed when we look at the individual tools below (Fig. 10).

Microblogging, social tagging and bookmarking are relatively favoured by younger researchers' conferencing, image and video sharing by the over 35s. These are of course much longer established technologies, designed for different applications. Perhaps there is a role difference here, with more senior academics perhaps being more likely to be involved in project negotiations with remote partners, or preparing presentations for conferences.

As in so many areas of new technology, it is tempting to try to fit these findings into a 'digital native' narrative, common wisdom being that the young are more familiar and comfortable with technological 
70
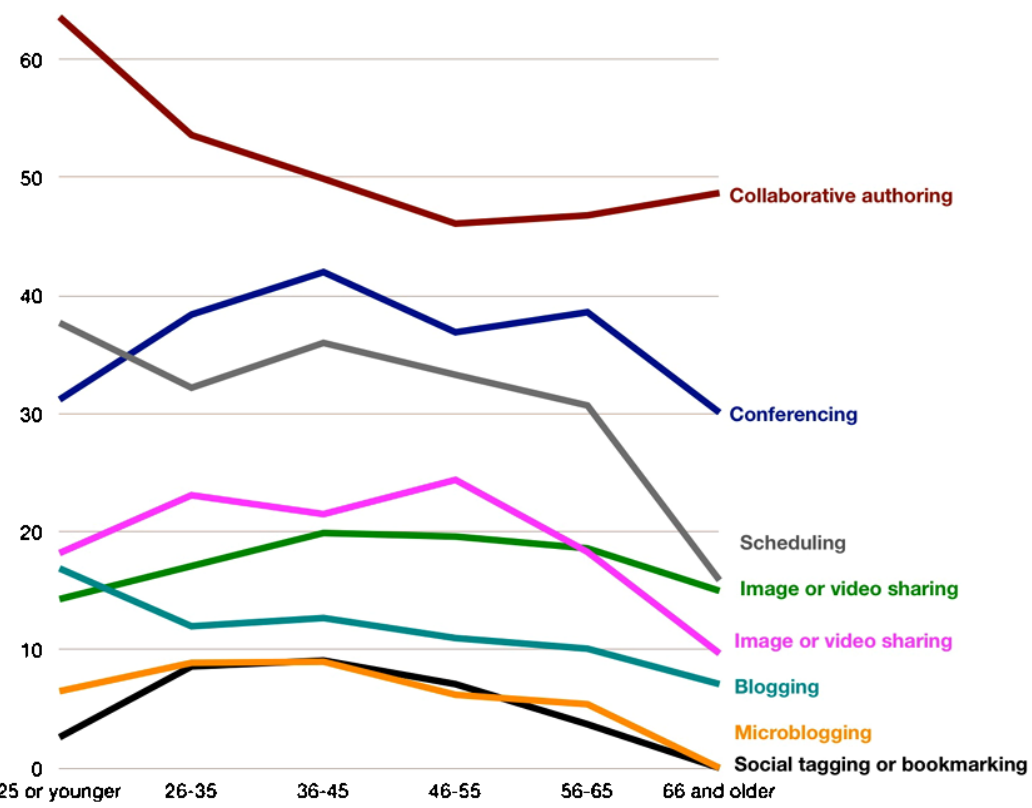

Fig. 11. Use of social media in research by age group. Percentage of users within age bands. (Colors are visible in the online version of the article; http://dx.doi.org/10.3233/ISU-2011-0623.)

Table 3

Use of social media in research by technology adoption behaviour. Percentages within technology adoption type

\begin{tabular}{lccccc}
\hline & \multicolumn{4}{c}{ Rogers' technology adoption type } \\
\cline { 2 - 6 } & Innovator & Early adopter & Early majority & Late majority & Laggard \\
\hline Non-users & $7.4 \%$ & $11.9 \%$ & $18.9 \%$ & $28.7 \%$ & $30.1 \%$ \\
Users & $92.6 \%$ & $88.1 \%$ & $81.1 \%$ & $71.3 \%$ & $69.9 \%$ \\
\hline
\end{tabular}

Cramer's $V=0.182$, approx. significance $=0.000$.

innovation. This would be a mistake, as CIBER's iconic Google Generation report found [5]. Figure 11 breaks out the age distribution of research users of each of the eight tools in more detail. It is very difficult to detect any general overall pattern. In fact, the surprise is that the distributions really are relatively flat: strikingly so if we were to disregard the over 65 age band. Yes, there is a broad distinction between the under and over 35s, and it is statistically significant: but it is absolutely not a case of yes or no.

As mentioned earlier one of the key demographic questions used in the survey is Rogers' well known typology of consumer behaviours towards new technology. With any new technology, there are time delays in people's adoption. Some (the innovators) are very quick off the mark and keen to experience new things as soon as they come onto the market. Others prefer to wait, possibly anticipating a later fall in prices, possibly because they want to wait until those technologies become established and their friends and colleagues tell them they are 'must haves'.

Table 3 shows clearly that Rogers' demographic is a very powerful predictor both of actual use and of awareness of social media tools. The very high levels of awareness among the early and late majority 
below suggest that we are looking at a moving target: it would not be at all surprising to find much higher levels of social media use across all age bands, were we to return to this survey and repeat it in twelve months' time. This is especially so, since the data in the previous figure show that social media are by no means a digital native phenomenon.

These points are emphasized in Fig. 12, another tree classification. Innovators and early adopters are 1.26 times more likely than late majority and laggards to be using social media professionally.

As well as a subject and age differences, take up of social media in research is patterned by geographic region (Fig. 13) lower in Asia and Northern America than in the rest of the world.

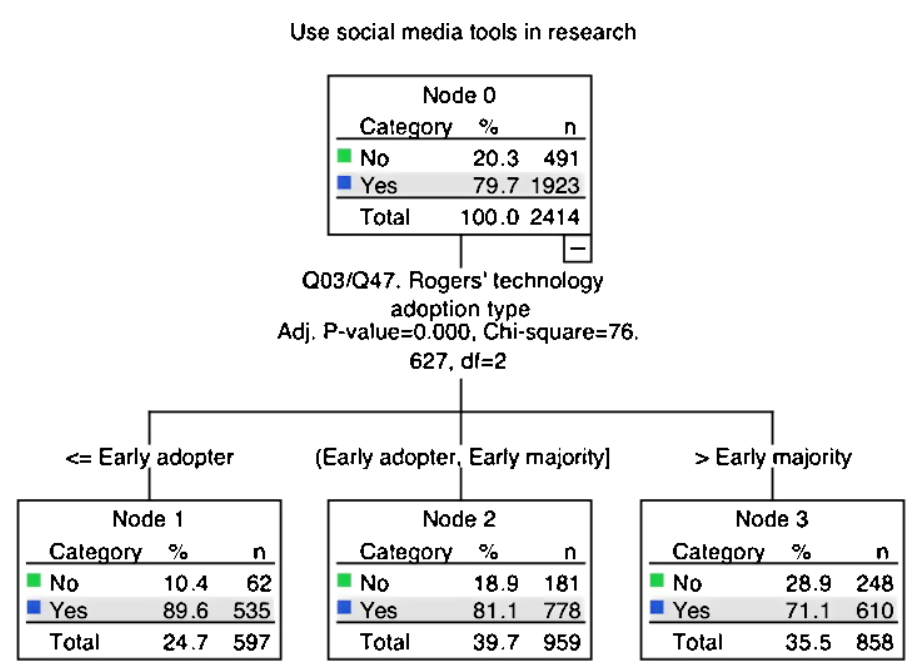

Fig. 12. Use of social media in research by technology adoption behaviour. Classification tree and chi-squared statistics. (Colors are visible in the online version of the article; http://dx.doi.org/10.3233/ISU-2011-0623.)

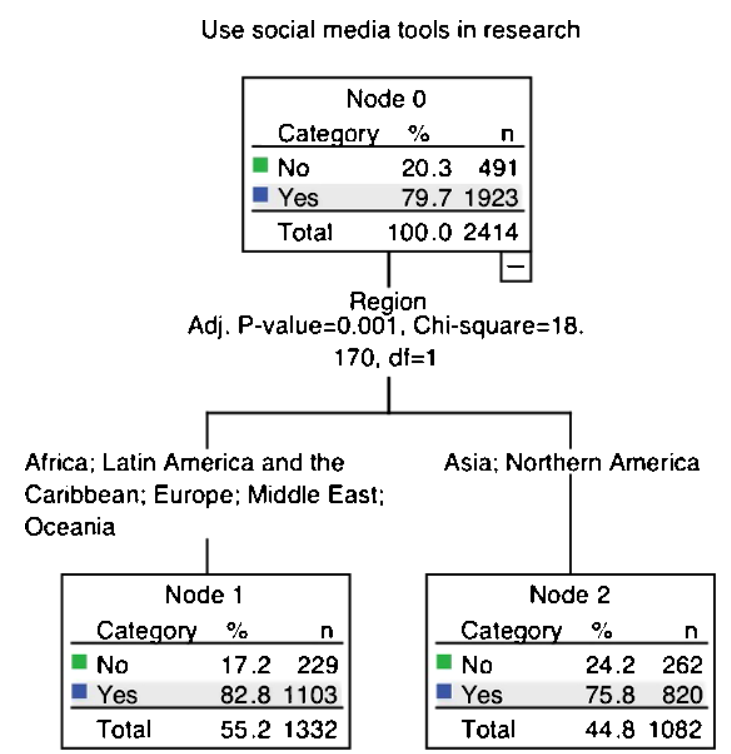

Fig. 13. Use of social media in research by broad geographic region. Classification tree and chi-squared statistics. (Colors are visible in the online version of the article; http://dx.doi.org/10.3233/ISU-2011-0623.) 
Table 4

Use and awareness of social media in research by geographic region. Percentages within region

\begin{tabular}{lccccccc}
\hline & \multicolumn{7}{c}{ Region } \\
\cline { 2 - 7 } & Africa & Latin America and Caribbean & Northern America & Asia & Europe & Oceania & Middle East \\
\hline Non-users & $15.4 \%$ & $18.1 \%$ & $24.5 \%$ & $23.3 \%$ & $16.6 \%$ & $18.8 \%$ & $20.4 \%$ \\
Users & $84.6 \%$ & $81.9 \%$ & $75.5 \%$ & $76.7 \%$ & $83.4 \%$ & $81.2 \%$ & $79.6 \%$ \\
\hline
\end{tabular}

Cramer's $V=0.068$, approx. significance $=0.012$.

The analysis in Table 4 is a little more detailed and finds Europe and Oceania (powered by Australia) as social media regional hotspots.

In conclusion, compared with our contrast group of academics who do not use social media in their research, users are:

- 1.91 times more likely to be innovators or early adopters.

- 1.27 times more likely to be found in the arts, humanities and social sciences.

- 0.67 times less likely to be found in biosciences and health.

- 1.68 times more likely to use a smartphone or other mobile device in their lives.

- 1.27 times more likely to say that their main style of research is to work with collaborators in different disciplines, and 1.58 times more likely to say that peers outside of their institution are extremely influential drivers of social media use.

- 1.23 times more likely to say that students are extremely influential drivers of social media use.

- 0.67 times less likely to say that their main style of research is to work with colleagues in their own department.

- 1.66 times more likely to strongly agree with the proposition that social media enhance academic esteem through the greater visibility it affords them.

- 2.11 times more likely to use an iPad in their lives.

These figures are a snapshot at one point in time, and they will be of interest to publishers and librarians in that they tell us something about the vanguard of early users. The main finding in this section is that it is simply not good enough to wrap social media use up with baggage about digital natives. Social media may not yet have fully invaded the research space, but the indicators here suggest that they are likely to make a very significant impact among most age groups over the next few years.

\subsection{Social media and the research life cycle}

A key aim of the survey was to focus in on current actual users of social media and how these tools actually fit into their research workflow, using the schematic below as a guide (Fig. 14). Although research does not happen in quite the tidy and sequential way that this diagram suggests, it is nonetheless a useful way to think about how tools are used, when, and for what purposes.

We asked questions using this framework for each of the eight categories of tools separately, and the resulting data is rich and complex. In fact, the complexity of the data is difficult to absorb in tabular form and is more easily comprehended in visual form. The next eight figures (Figs 15-22) are radar or 'spider' diagrams and they need a little explanation. Each figure represents a different social media tools. The outer points on the wheel correspond to the diagram above: reasons why that particular tool might be used (or not used) in a research project and at what point. The spokes of the wheel are what the users tell us about perceived usefulness on a four point scale where 4 - extremely useful. 


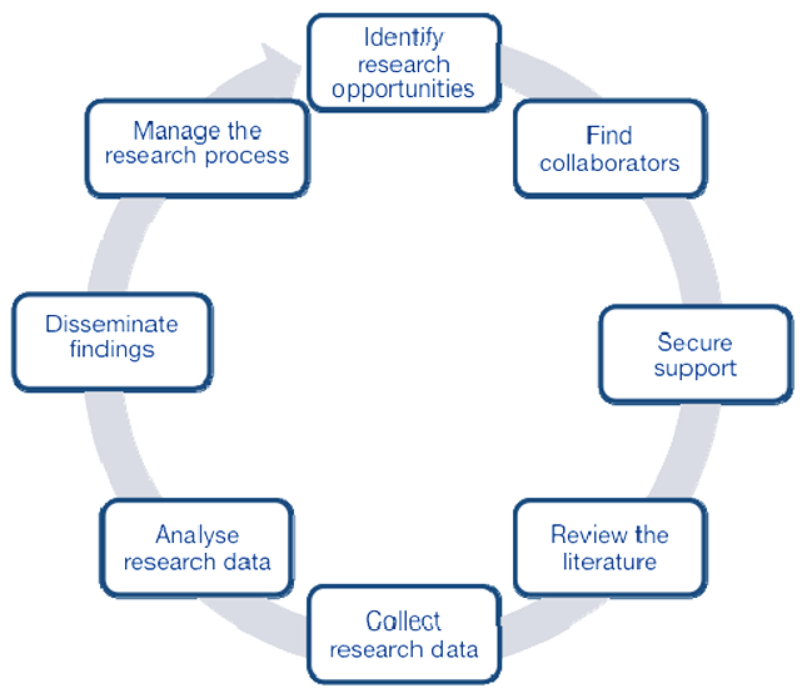

Fig. 14. The research lifecycle. Schematic. (Colors are visible in the online version of the article; http://dx.doi.org/10.3233/ISU2011-0623.)

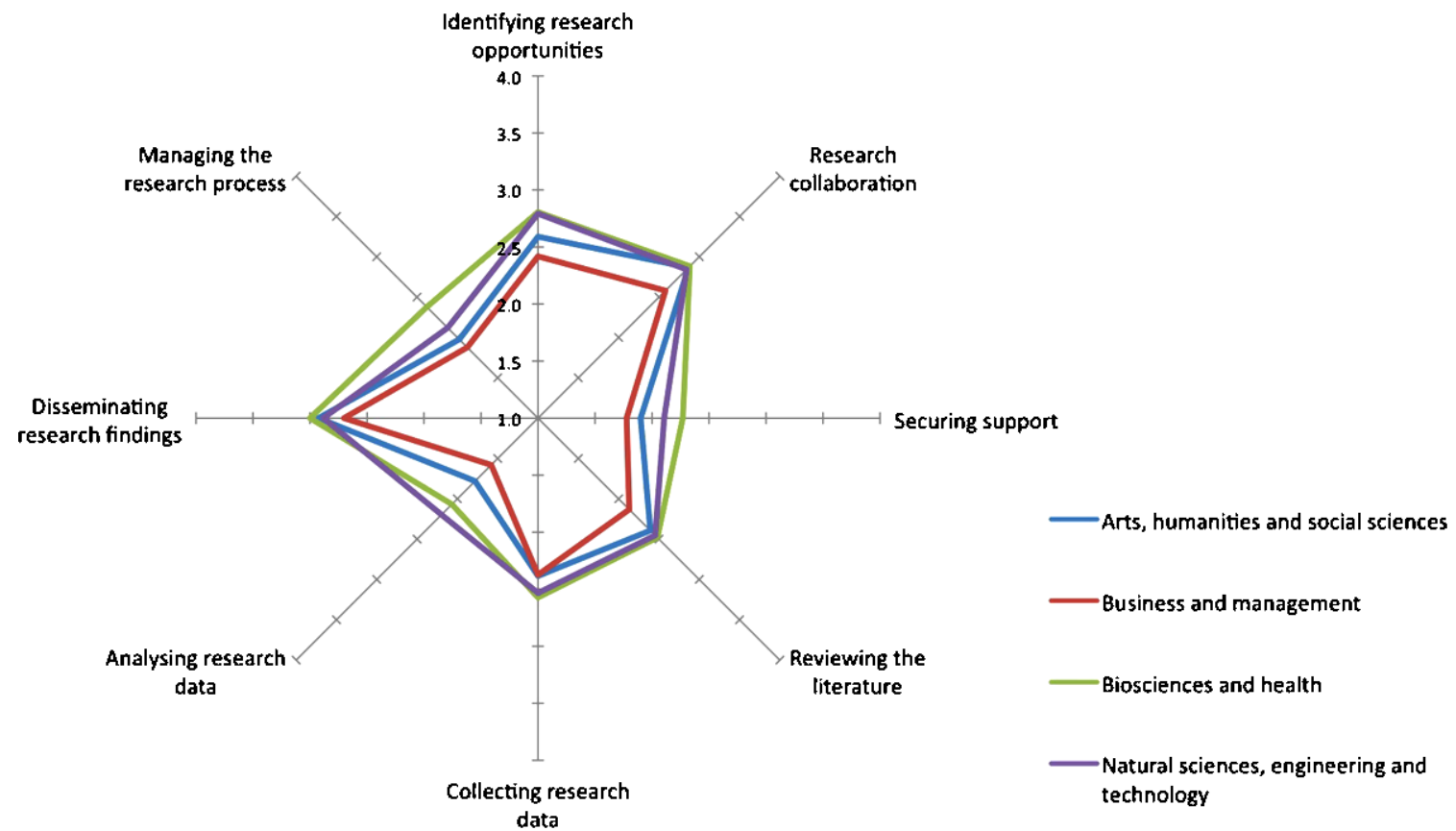

Fig. 15. Social networking and the research lifecycle. Perceived usefulness on a four-point scale where $1-$ not at all useful and 4 - extremely useful. (Colors are visible in the online version of the article; http://dx.doi.org/10.3233/ISU-2011-0623.)

The coloured lines represent the four broad subject categories employed in this study. Taking the first (Fig. 15) as an example, we can see instantly that biosciences and health occupy the largest area (i.e., these users find social networking generally more useful than the other disciplines), business and management the smallest area (i.e., less useful). The shape of the web is very similar for all four subjects 


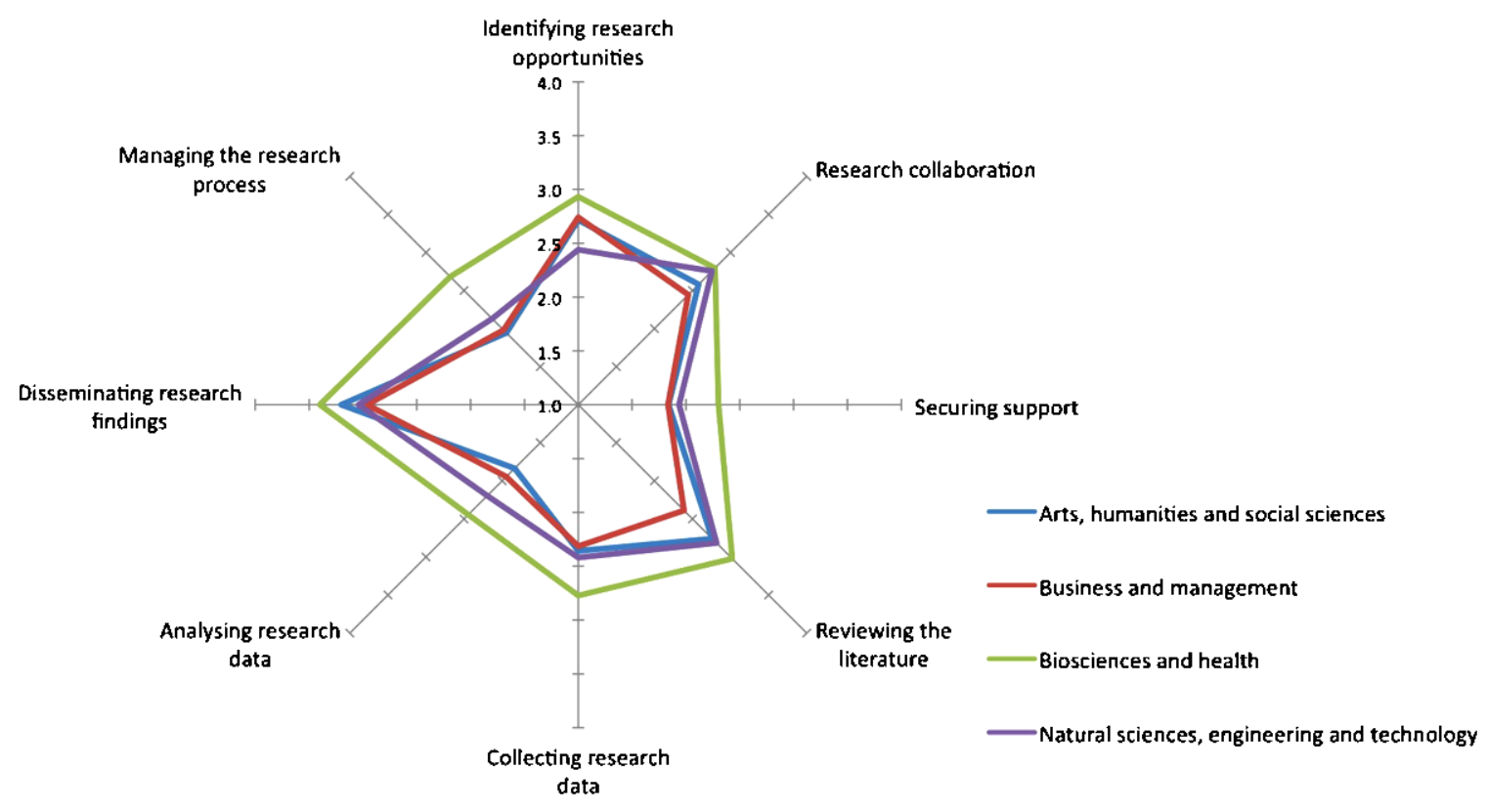

Fig. 16. Blogging and the research lifecycle. Perceived usefulness on a four-point scale where 1 - not at all useful and $4-$ extremely useful. (Colors are visible in the online version of the article; http://dx.doi.org/10.3233/ISU-2011-0623.)

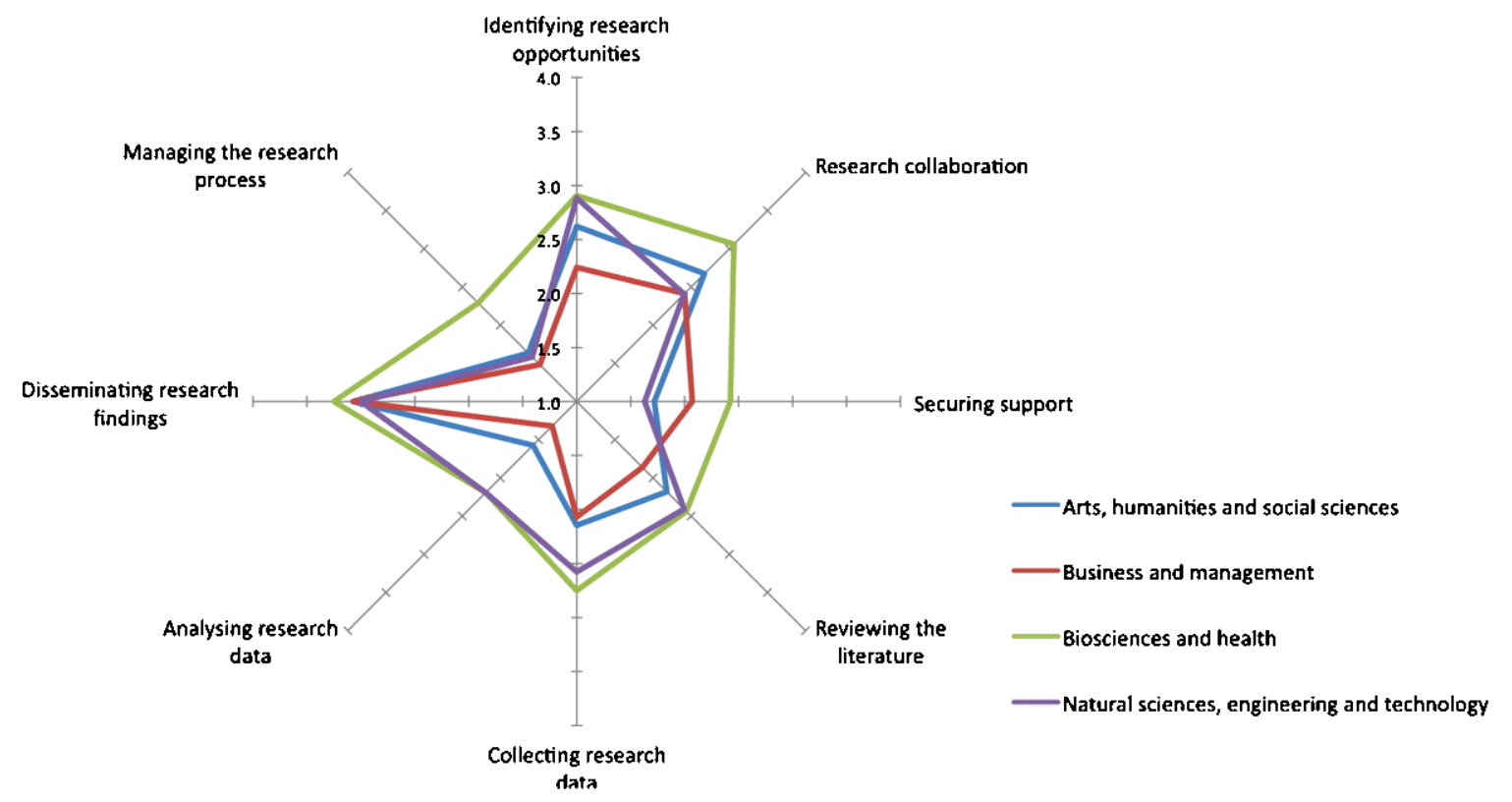

Fig. 17. Microblogging and the research lifecycle. Perceived usefulness on a four-point scale where $1-$ not at all useful and $4-$ extremely useful. (Colors are visible in the online version of the article; http://dx.doi.org/10.3233/ISU-2011-0623.)

and the perception is that social networking is most useful for the dissemination of research findings, in research collaboration and, perhaps surprisingly, in helping to identify research opportunities. A very different pattern can be seen in the case of Fig. 20 (scheduling tools) which self-evidently finds major 


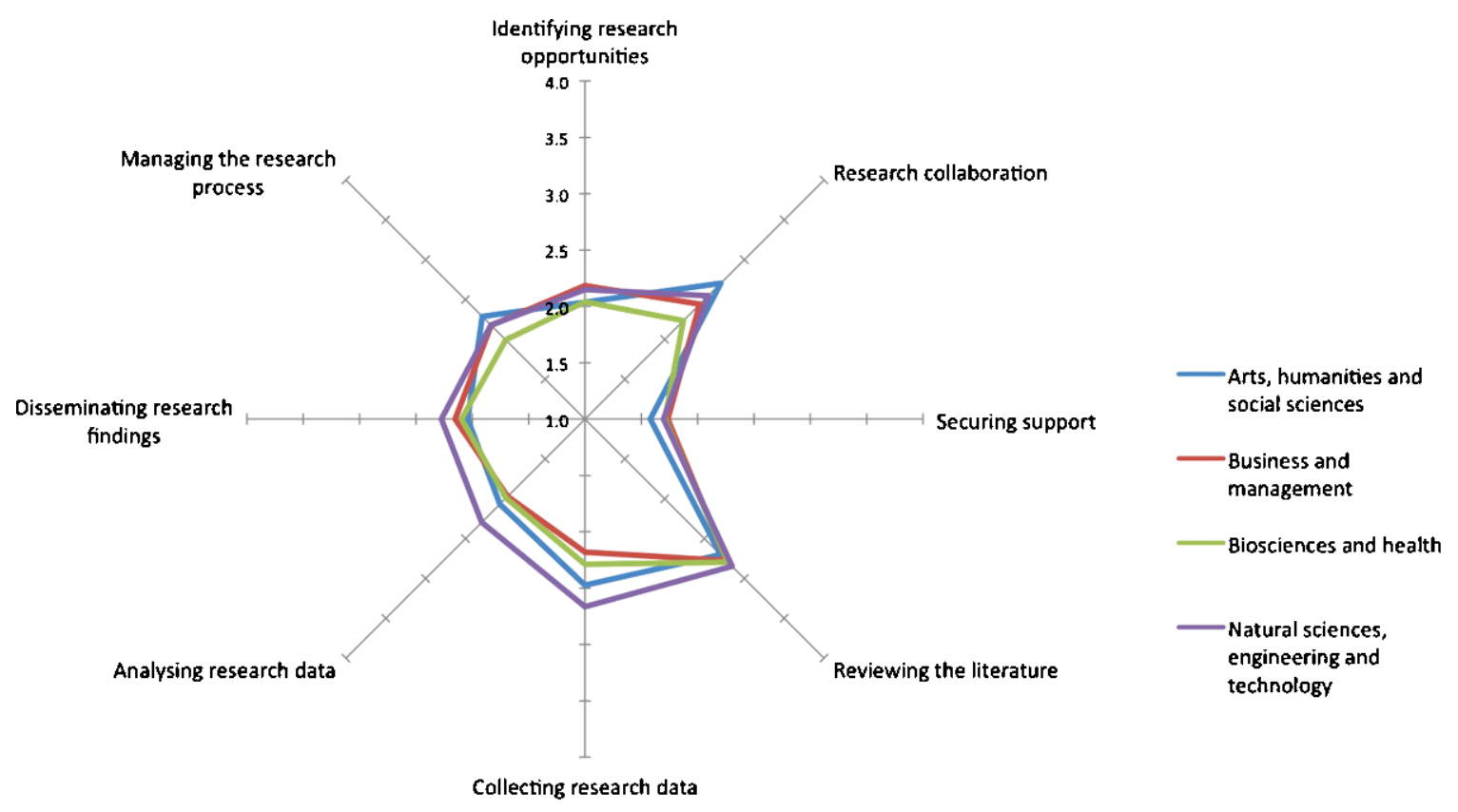

Fig. 18. Collaborative authoring and the research lifecycle. Perceived usefulness on a four-point scale where $1-$ not at all useful and 4 - extremely useful. (Colors are visible in the online version of the article; http://dx.doi.org/10.3233/ISU-2011-0623.)

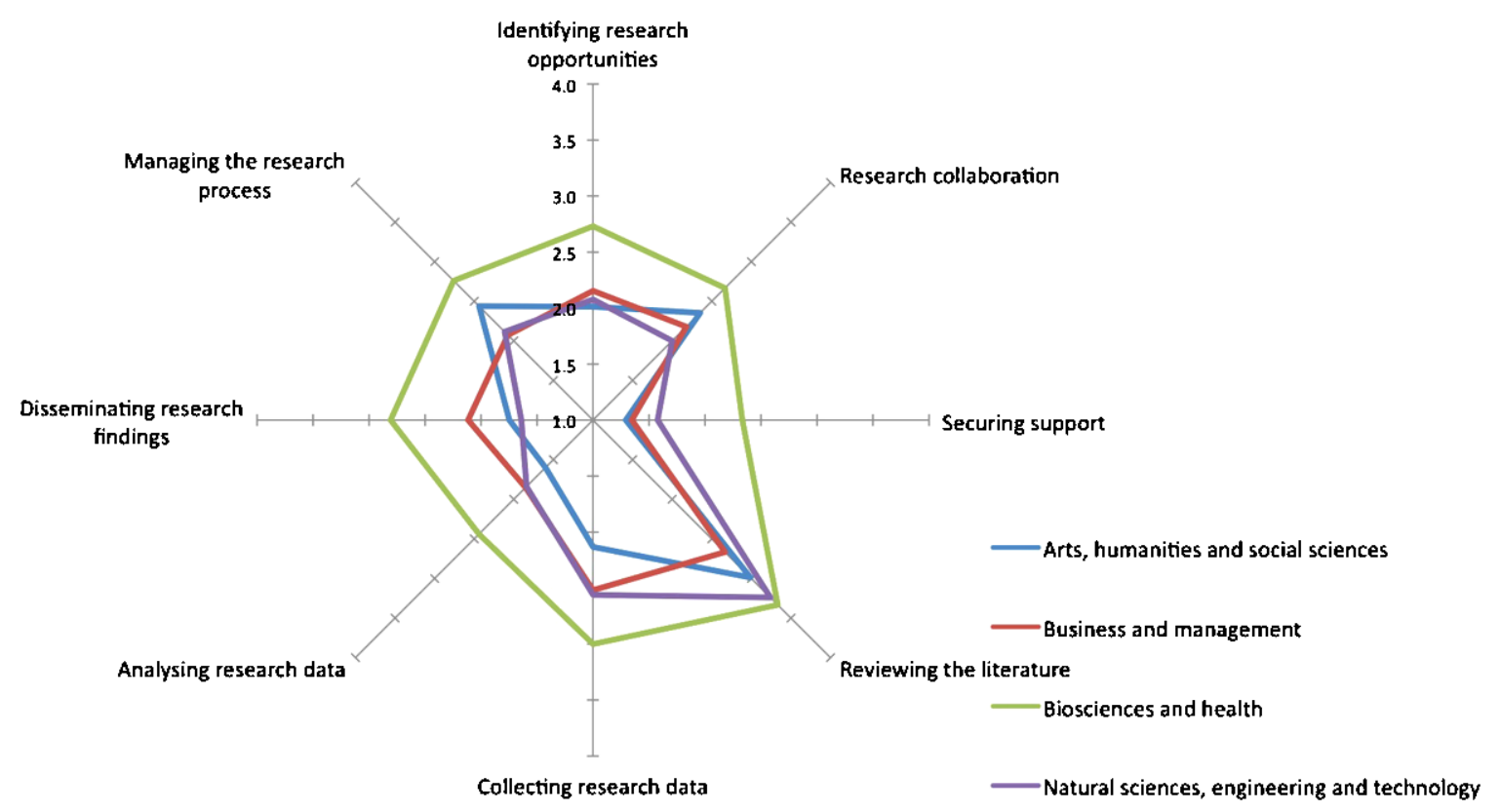

Fig. 19. Social tagging and bookmarking and the research lifecycle. Perceived usefulness on a four-point scale where $1-$ not at all useful and 4 - extremely useful. (Colors are visible in the online version of the article; http://dx.doi.org/10.3233/ ISU-2011-0623.)

application in research management and collaboration but nowhere else. Two overall impressions are formed by quickly scanning these diagrams. The first is the very high incidence of points that lie in the 


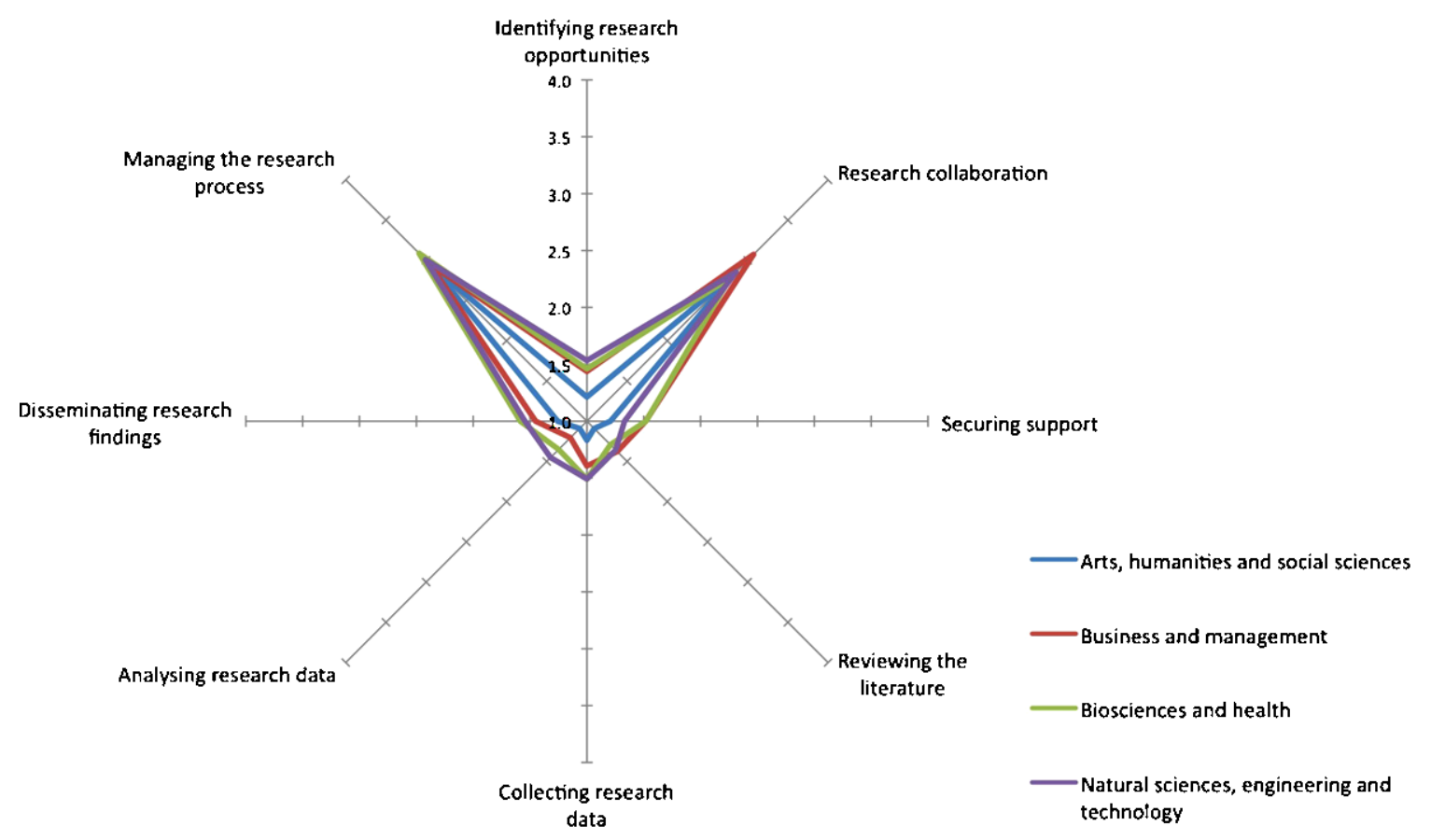

Fig. 20. Scheduling tools and the research lifecycle. Perceived usefulness on a four-point scale where $1-$ not at all useful and 4 - extremely useful. (Colors are visible in the online version of the article; http://dx.doi.org/10.3233/ISU-2011-0623.)

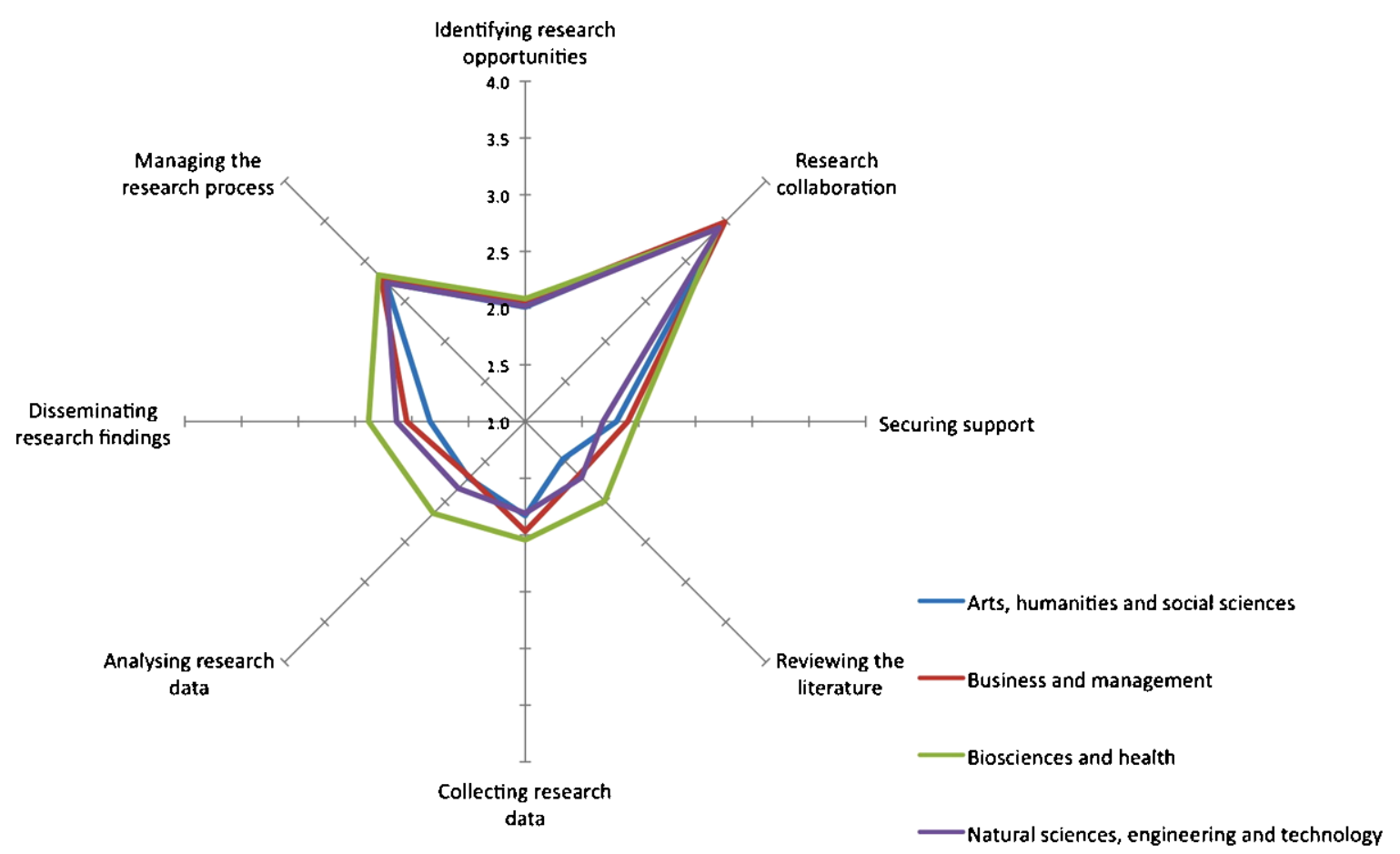

Fig. 21. Conferencing tools and the research lifecycle. Perceived usefulness on a four-point scale where $1-$ not at all useful and 4 - extremely useful. (Colors are visible in the online version of the article; http://dx.doi.org/10.3233/ISU-2011-0623.) 


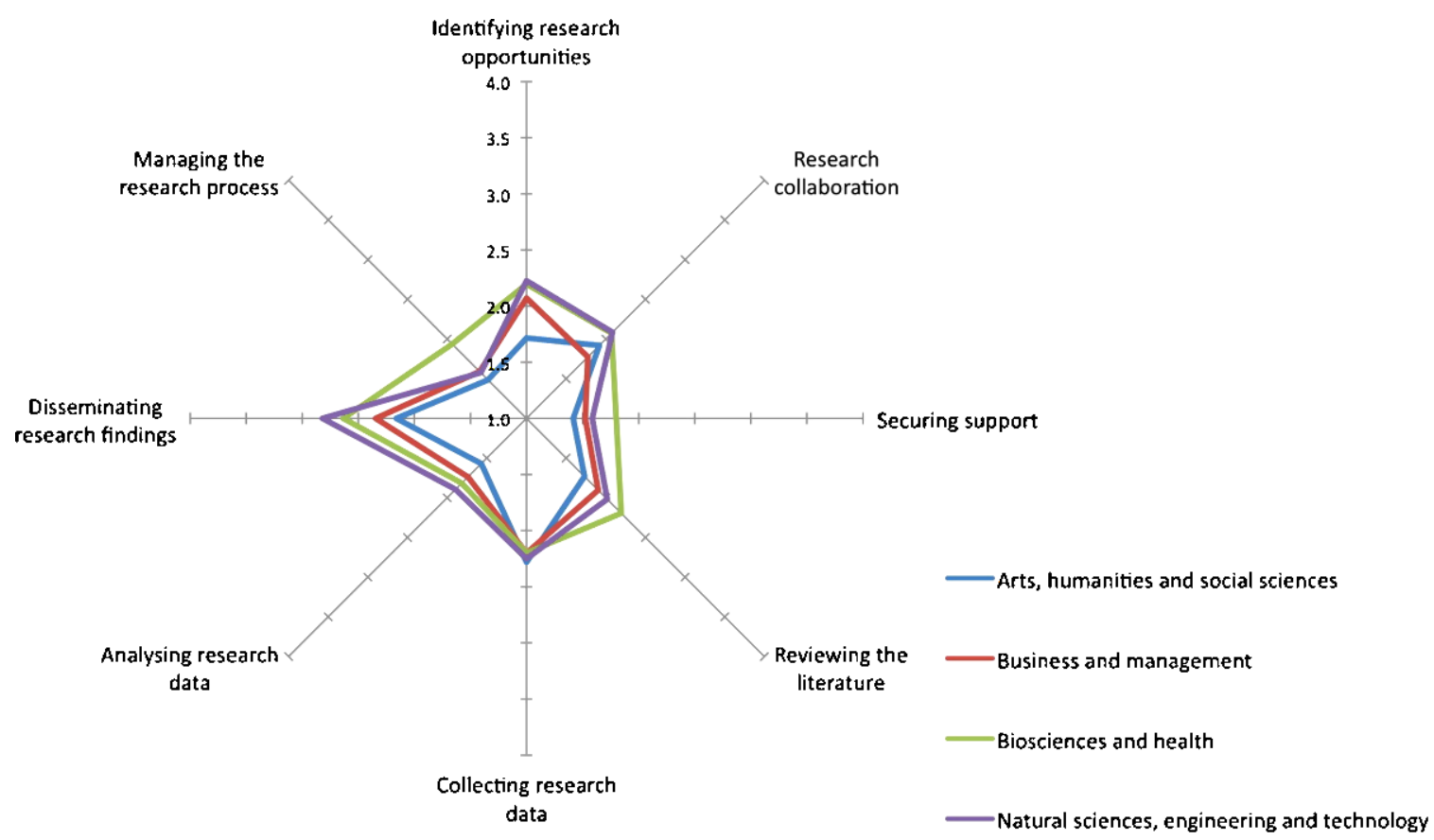

Fig. 22. Image or video sharing and the research lifecycle. Perceived usefulness on a four-point scale where $1-$ not at all useful and 4 - extremely useful. (Colors are visible in the online version of the article; http://dx.doi.org/10.3233/ISU-2011-0623.)

range 2 (useful) to 3 (very useful). Social media have found a place in the research workflow for many academics and are proving their worth. The other impression is that with the exception of scheduling tools, which have a very limited and specific use, social media are generally finding useful application at all phases of the research lifecycle.

Disseminating research findings is clearly a key function for social networking.

Blogging is also largely used to disseminating research findings; it is also important in reviewing the literature, although not so much for business management.

Microblogging is also largely used to disseminating research findings; it has a role in research collaboration too.

The natural sciences are the big users of collaborative authoring, which has an important role in reviewing the literature.

Social tagging, one of the least popular social media tools, is not surprisingly used for reviewing the literature and mostly used by the biosciences.

Scheduling tools are used for managing the research process and collaboration.

Conferencing tools are used to enable research collaboration, by all subject groups.

Image and video sharing tools assist in disseminating research findings, especially in the natural sciences.

\subsection{The social media brands}

For each group of social media tools, we invited respondents to enter their preferred tools in a free text box. Represented as a word cloud (Fig. 23) we see a very familiar list of household brands, in which Skype, Wikipedia, Google Docs and YouTube feature strongly, and not tools developed specifically for 


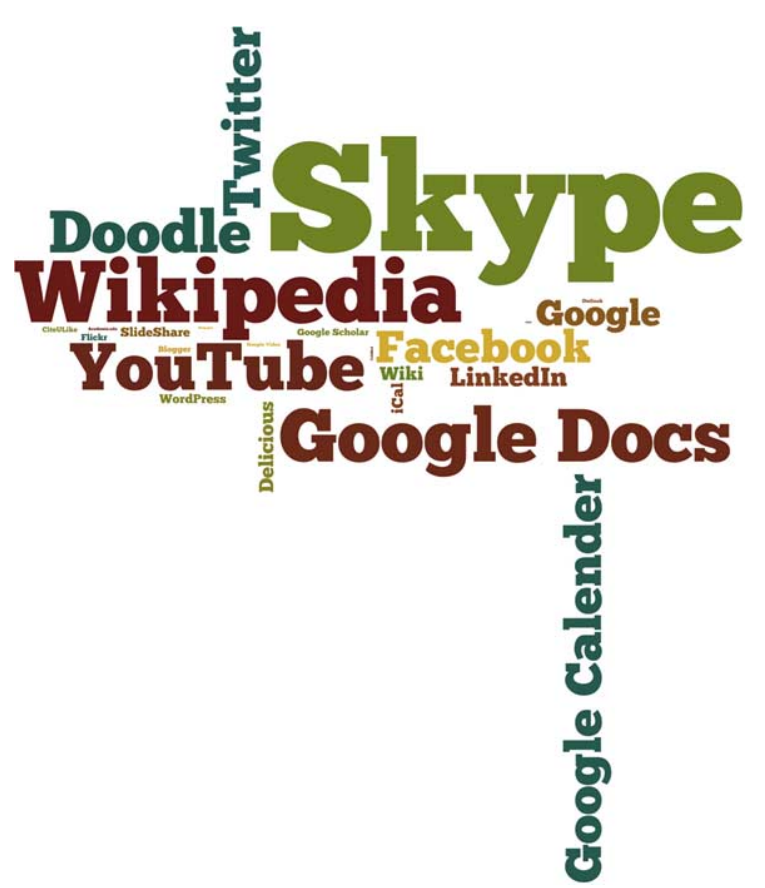

Fig. 23. Social media tools most frequently mentioned. Word cloud where font size is proportion to frequency of mentions. (Colors are visible in the online version of the article; http://dx.doi.org/10.3233/ISU-2011-0623.)

research lifecycle management. It seems that researchers, who also use these generic brands in their personal lives outside work, are appropriating them for their research. Does this mean that there may be a gap in the marketplace for more bespoke, custom tools? We are exploring this question further in the focus groups.

\subsection{Drivers, perceived benefits and barriers to social media use in research}

In this section, we look at the factors that tend to dispose researchers favourably towards social media, or turn them off.

\section{Drivers}

Figure 24 tabulates the reasons why researchers use social media. The most important are personal initiative, the fact that technology means these tools are easily available and can be used, and their perceived contribution to faster, more efficient research.

\section{Perceived benefits}

Researchers associate a number of perceived benefits with social media use (Fig. 25) and the key really is the ability they offer to be able to communicate effectively with diverse audiences, often at remote distances.

These findings suggest that researchers associate social media positively with a wide range of benefits.

\section{Barriers}

We also asked respondents seven questions about factors that perhaps inhibited them from using social media in their research. Figure 26 tabulates these findings. Lack of time is the most cited factor. 


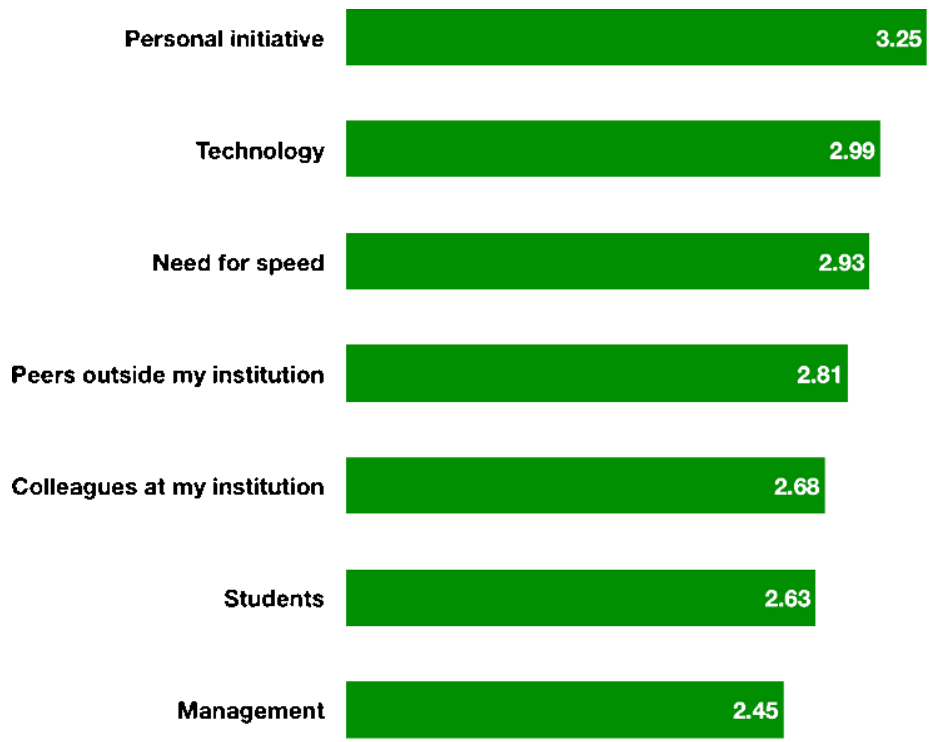

Fig. 24. Drivers of social media use in research. Mean preference scores where 0 - not at all influential and 4 - extremely influential. (Colors are visible in the online version of the article; http://dx.doi.org/10.3233/ISU-2011-0623.)

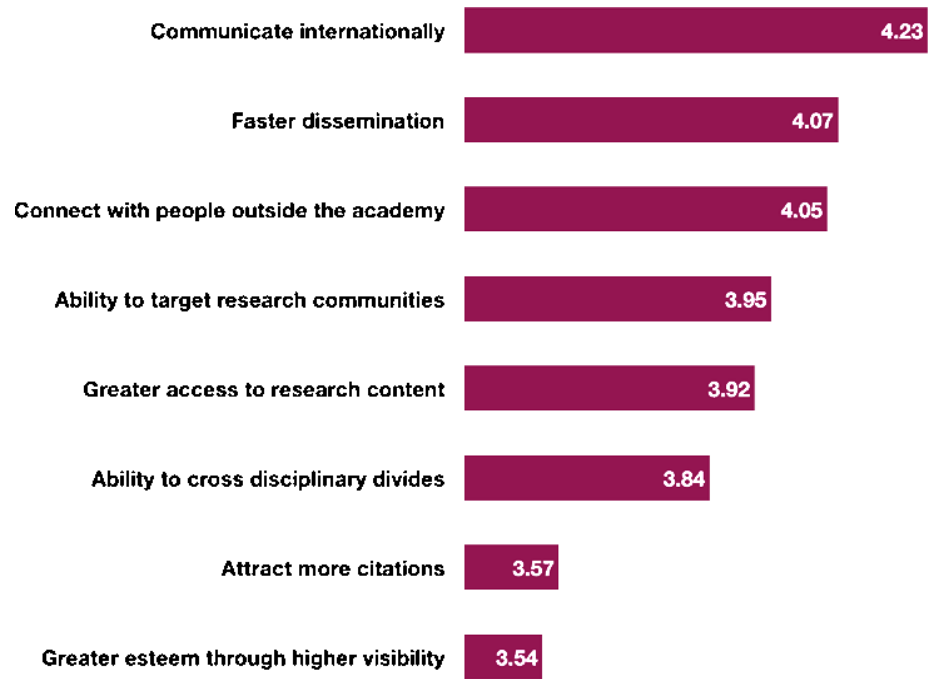

Fig. 25. Perceived benefits of social media use in research. Mean agreement scores, where $1-$ strongly disagree, 5 - strongly agree. (Colors are visible in the online version of the article; http://dx.doi.org/10.3233/ISU-2011-0623.)

\subsection{Discovery, access and dissemination}

Of course, we have to understand social media use in the broader scholarly communication context of how academics discover, access and disseminate scholarly information.

We asked researchers to rate their preferences for the different ways they can search for and discover scholarly content (Fig. 27). By far their most favoured route is to search the open web, followed by licensed e-content made available through their institutional library. The error bars represent $95 \%$ confidence intervals around the mean, so we can see that there is no discernible difference between social 


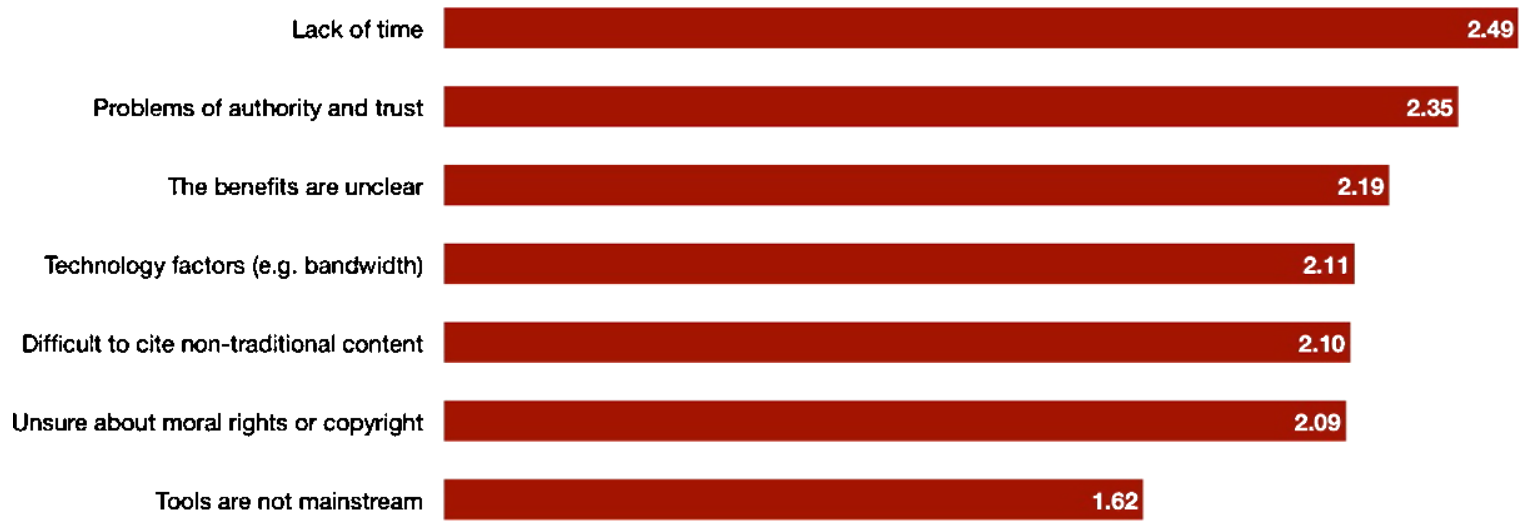

Fig. 26. Barriers to social media in research. Mean preference scores where $0-$ not at all influential and $4-$ extremely influential. (Colors are visible in the online version of the article; http://dx.doi.org/10.3233/ISU-2011-0623.)

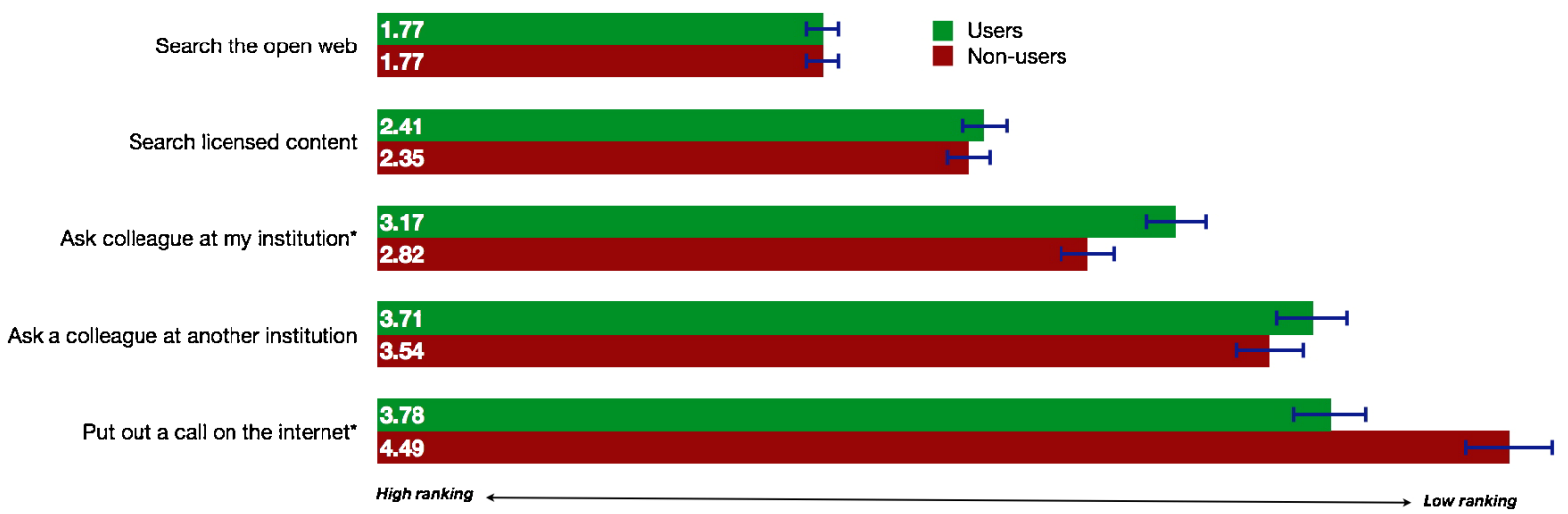

Fig. 27. Scholarly information discovery preferences: social media users and non-users. Preferences expressed on a scale where 1 - most favoured and 5 - least favoured. (Colors are visible in the online version of the article; http://dx.doi.org/10.3233/ ISU-2011-0623.)

media users and our contrast group in this respect. Both groups are also equally likely to consult and expert at another institution. Where they do differ is that the social media active researcher is much more likely to put out a general call for information, perhaps on a listserv or a social network. They are also less likely to seek out an expert in their own institution. Whether this indicative of a degree of isolation where they work, or whether they just think in broader terms is an issue for focus group follow up.

When we turn to their preferred modes for disseminating research, again we find no difference in terms of the way that users and non-users of social media regard traditional publishing channels (Fig. 28). Long-established formats such as the journal, conference proceedings and edited books are still king. What is different, though, is that active social media users are far more likely to use the internet as a complementary activity, disseminating their findings through email lists and web groups, personal web pages, wikis, blogs, social networks and Twitter. This is unsurprising, but the rapid rise of personal dissemination brings with it some big implications for publishers (especially) and librarians.

We can also see, in Fig. 29, that there is no difference in the intention behind research dissemination. Social media users and the contrast group are singing from the same hymn sheet here, everyone aiming to reach a number of different audiences and quickly. 


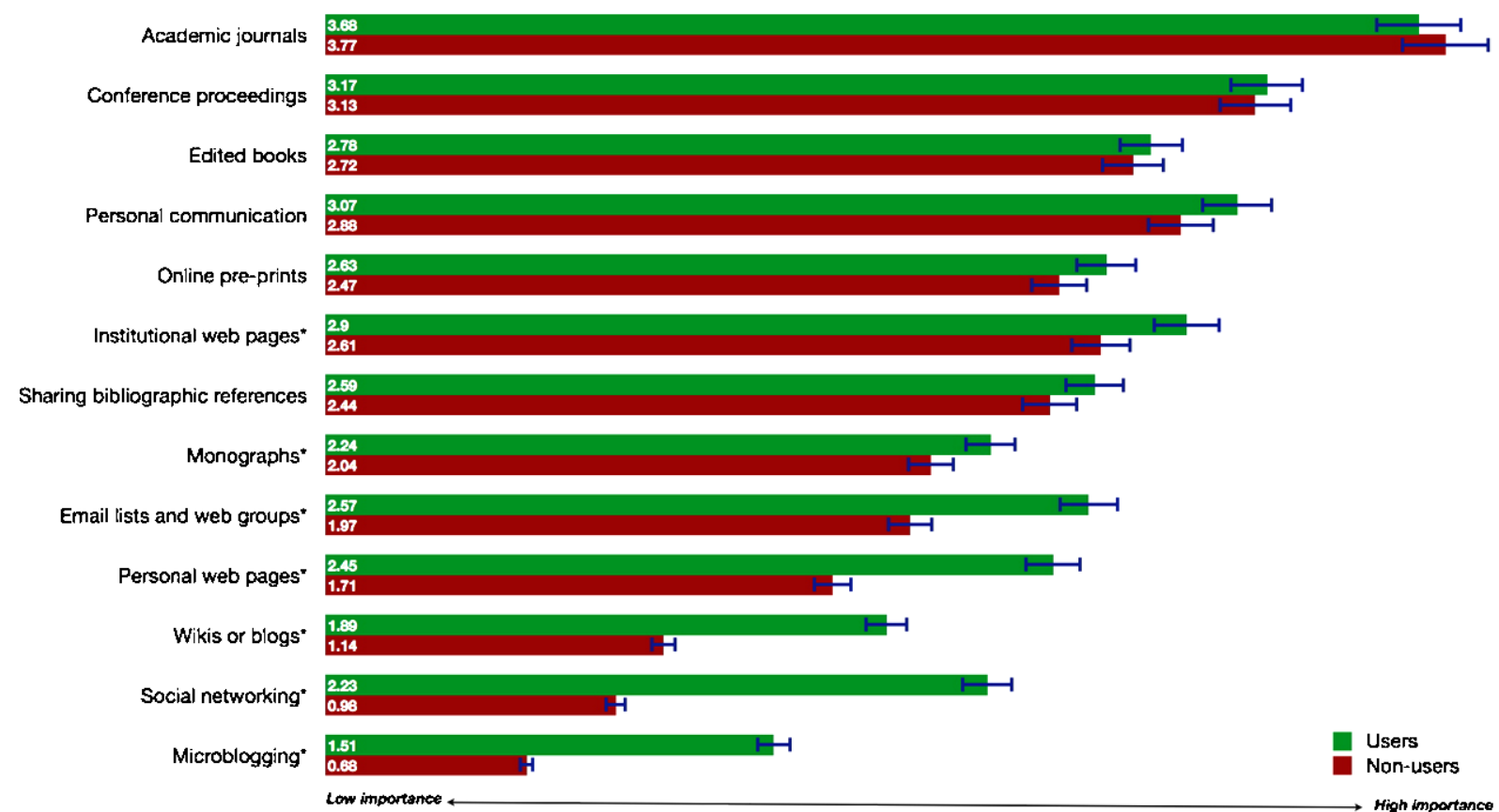

Fig. 28. Importance attached to specific dissemination channels: social media users and non-users. Preferences expressed on a scale where 1 - not at all important and 4 - extremely important. (Colors are visible in the online version of the article; http://dx.doi.org/10.3233/ISU-2011-0623.)

Reaching fellow specialists

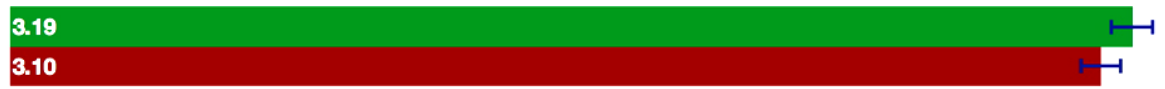

Reaching as many people as possible*

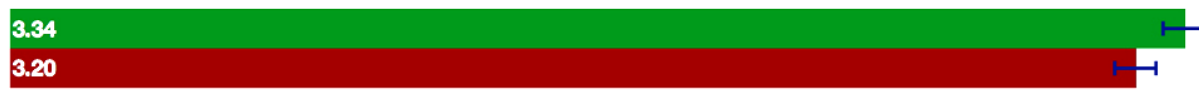

Speed of dissemination

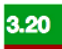

Reaching research sponsors

- Users

Non-users

Fig. 29. Intentions associated with dissemination: social media users and non-users. Preferences expressed on a scale where 1 - not at all important and 4 - extremely important. (Colors are visible in the online version of the article; http://dx.doi.org/10.3233/ISU-2011-0623.)

\section{Conclusions}

Social media have found serious application at all points of the research lifecycle. The three most popular social media tools in a research setting are those for collaborative authoring, conferencing, and scheduling meetings.

Awareness of social media among members of the research community is high, but there is a large gap between awareness and actual use for the majority of tools. 
Researchers in business, health, the biosciences, and the arts and humanities are less likely to use social media professionally than their peers in other parts of the academy.

Researchers under 35 are generally more likely to use at least one social media application than the over 35s. This finding is a broad generalization of a much more complex picture when we look at specific tools, which show strikingly different patterns of take up by age. We should be very careful indeed of applying 'digital native' narratives to social media. As we have said many times before, the future is now!

Age is in fact a rather poor predictor of social media use in a research context. Rogers' well-known model of technology adoption offers a far better explanation for take up: innovators and early adopters are 1.26 times more likely to use social media professionally.

Professional users of social media are 1.68 times more likely to use a smartphone or other mobile device than non-users; and 2.11 times more likely to use an iPad. This is consistent with the previous key finding.

Researchers are using social media tools to support every phase of the research lifecycle: from identifying research opportunities to disseminating findings at the end. They may not be the same tools, and they are certainly not the same researchers, but social media are most definitely making an impact on scholarly workflow.

The most popular tools used in a professional research context tend to be mainstream anchor technologies or 'household brands', like Skype, Google Docs, Twitter and YouTube. Researchers seem to be largely appropriating generic tools rather than using specialist or custom-built solutions and both publishers and librarians need to adapt to this reality. Is this a sign, perhaps, that there may be a gap in the market for simple bespoke tools?

The key driver for the take up of social media is pressure exerted by peers outside of the researcher's own institution. Social media are helping to fulfill the demand for cheap, instant communication between researchers fuelled by the growth of collaborative and interdisciplinary research.

Use of social media is usually down to personal initiative, so a clear understanding of the capabilities and benefits of these tools is essential. Time-poor researchers are still unclear about the benefits of social media and this represents a major barrier to their take up. They also have serious concerns about the authenticity of crowd-sourced information.

Users and non-users of social media express almost identical preferences when they look for scholarly information. Their first preference is for the open web, followed by searching licensed e-content through their libraries, followed by asking a colleague. The only difference we could detect in this survey between users and non-users is that the former are more likely to put out a general call for information on a list serv or social network.

We find a similar pattern with regard to research dissemination. The traditional channels (especially journals, conference proceedings and edited books) are greatly and equally favoured by both social media users and non-users over informal channels such as blogs. Researchers continue to back dissemination routes that they know and trust. It is clear that social media users see informal tools as a complement to the existing system of scholarly publishing, not as a replacement. As a result, personal dissemination is on a steep upward curve, with implications for publishers especially.

Researchers, especially senior researchers, want above all for publishers to make content readable on all platforms. This, together with more progress in linking articles to their underlying data. They want the basics to work well, not more 'bells and whistles'.

Researchers also sent a clear message to librarians. At the top of their wish list, and by a big margin, is a desire to be able to search across the full text of all locally-held licensed e-content using a simple 
interface like Google. This is seen as a much greater potential benefit than libraries moving into the social media space by offering users, for example, an opportunity to socially tag the library catalogue.

The authors are grateful to Emerald Group Publishing, the project's sponsor, for access to their mailing lists. Thanks also go to Taylor \& Francis, Wiley-Blackwell, Cambridge University Press, the Charleston Library Conference, University College London and Wolters Kluwer for their generous support in kind in the form of access to their mailing lists.

The full survey is available from www.ucl.ac.uk/infostudies/research/ciber.

\section{References}

[1] APE 2011 Preconference day, available at: www.ape2011.eu.

[2] RIN, If you build it, will they come? How researchers perceive and use web 2.0, 2010, available at: http://www.rin.ac. uk/our-work/communicating-and-disseminating-research/use-and-relevance-web-20-researchers.

[3] E.M. Rogers, Diffusion of Innovations, Free Press, Glencoe, 1962.

[4] I. Rowlands and D. Nicholas, The economic downturn and libraries: an international survey, Learned Publishing 23(2) (2010), 144-156.

[5] I. Rowlands, D. Nicholas, P. Huntington, P. Williams, B. Gunter, C. Tenopir, R. Withey, H. Jamali and M. Fieldhouse, The information behaviour of the researcher of the future (GoogleGeneration), 2007, available at: http://www.ucl.ac.uk/infostudies/research/ciber/downloads/ggexecutive.pdf. 